\title{
Environmental signals rather than layered ontogeny imprint the function of type 2 conventional dendritic cells in young and adult mice
}

\author{
Nikos E. Papaioannou ${ }^{1,2}$, Natallia Salei ${ }^{1,2}$, Stephan Rambichler ${ }^{1,2}$, Kaushikk Ravi ${ }^{1,2}$, Jelena Popovic (1) 1,2, \\ Vanessa Küntzel ${ }^{1,2}$, Christian H. K. Lehmann (10 3,4, Remi Fiancette ${ }^{5}$, Johanna Salvermoser ${ }^{1,2}$, \\ Dominika W. Gajdasik ${ }^{5}$, Ramona Mettler ${ }^{1,2}$, Denise Messerer ${ }^{6}$, Joana Carrelha ${ }^{7}$, Caspar Ohnmacht ${ }^{8}$, \\ Dirk Haller (D) 9,10, Ralf Stumm (1D 11, Tobias Straub (10 12, Sten Eirik W. Jacobsen 7,13, Christian Schulz (D) 6,14, \\ David R. Withers (10 ${ }^{5}$, Gunnar Schotta (1) ${ }^{15,16}$, Diana Dudziak ${ }^{3,4,17,18}$ \& Barbara U. Schraml (1) ${ }^{1,2 凶}$
}

Conventional dendritic cells ( $C D C$ ) are key activators of naive T cells, and can be targeted in adults to induce adaptive immunity, but in early life are considered under-developed or functionally immature. Here we show that, in early life, when the immune system develops, cDC2 exhibit a dual hematopoietic origin and, like other myeloid and lymphoid cells, develop in waves. Developmentally distinct $C D C 2$ in early life, despite being distinguishable by fate mapping, are transcriptionally and functionally similar. CDC2 in early and adult life, however, are exposed to distinct cytokine environments that shape their transcriptional profile and alter their ability to sense pathogens, secrete cytokines and polarize T cells. We further show that $\mathrm{CDC2}$ in early life, despite being distinct from CDC2 in adult life, are functionally competent and can induce $T$ cell responses. Our results thus highlight the potential of harnessing CDC2 for boosting immunity in early life.

\footnotetext{
${ }^{1}$ Faculty of Medicine, Biomedical Center, Institute for Cardiovascular Physiology and Pathophysiology, LMU Munich, 82152 Planegg-Martinsried, Germany. ${ }^{2}$ Walter-Brendel-Centre of Experimental Medicine, University Hospital Munich, LMU Munich, 82152 Planegg-Martinsried, Germany. ${ }^{3}$ Laboratory of Dendritic Cell Biology, Department of Dermatology, University Hospital Erlangen, Friedrich-Alexander University of Erlangen-Nürnberg, Erlangen, Germany.

${ }^{4}$ Medical Immunology Campus Erlangen, University Hospital of Erlangen, Friedrich-Alexander-University (FAU) of Erlangen-Nürnberg, Erlangen, Germany. ${ }^{5}$ Institute of Immunology and Immunotherapy, College of Medical and Dental Sciences, University of Birmingham, Birmingham, UK. ${ }^{6}$ Medizinische Klinik und Poliklinik I, University Hospital Munich, LMU Munich, 81377 Munich, Germany. ${ }^{7}$ Haematopoietic Stem Cell Biology Laboratory, MRC Molecular Haematology Unit, MRC Weatherall Institute of Molecular Medicine, Radcliffe Department of Medicine, University of Oxford, Oxford, UK. ${ }^{8}$ Center of Allergy and Environment, Helmholtz Center and Technical University of Munich, 80802 Munich, Germany. ${ }^{9}$ ZIEL-Institute for Food and Health, Technische Universität München, Freising, Germany. ${ }^{10}$ Chair of Nutrition and Immunology, Technische Universität München, Freising, Germany. ${ }^{11}$ Institute of Pharmacology and Toxicology, Jena University Hospital, Jena, Germany. ${ }^{12}$ Core Facility Bioinformatics, Biomedical Center, LMU Munich, 82152 PlaneggMartinsried, Germany. ${ }^{13}$ Department of Medicine Huddinge, Center for Hematology and Regenerative Medicine and Department of Cell and Molecular Biology, Karolinska Institutet, Stockholm, Sweden. ${ }^{14}$ DZHK (German Center for Cardiovascular Research), Partner Site Munich Heart Alliance, 80802 Munich, Germany. ${ }^{15}$ Faculty of Medicine, Center for Integrated Protein Science Munich, LMU Munich, 82152 Planegg-Martinsried, Germany. ${ }^{16}$ Faculty of Medicine, Division of Molecular Biology, Biomedical Center, LMU Munich, 82152 Planegg-Martinsried, Germany. ${ }^{17}$ Deutsches Zentrum Immuntherapie (DZI), Erlangen, Germany. ${ }^{18}$ Comprehensive Cancer Center Erlangen-European Metropolitan Area of Nuremberg (CCC ER-EMN), Erlangen, Germany.

凶email: barbara.schraml@bmc.med.Imu.de
} 
$\mathrm{V}$ accination is a reliable means of inducing protective immunity but it can have limited efficacy in infants ${ }^{1}$. The newborn immune system exhibits quantitative and qualitative differences compared to adult hosts that ultimately result in dampened immune responses in early life, which are necessary to tolerate the sudden encounter with commensal microbes and environmental antigens ${ }^{2,3}$. The unique features of the early life immune system also leave infants at increased risk of infection ${ }^{3}$. Antigen presentation and priming of T cells are pre-requisites for adaptive immune responses and the establishment of protective immunity. Improving $\mathrm{T}$-cell priming by tailoring the design of vaccines towards the age-specific immune parameters of neonates and infants has therefore been suggested as a possibility to boost vaccination efficacy and immunity in early life ${ }^{3,4}$.

Classical or conventional dendritic cells (cDCs) are potent activators of naive $\mathrm{T}$ cells that have successfully been targeted to induce adaptive immune responses in adults ${ }^{5-8}$. In early life, however, these cells are considered under-developed or functionally immature. In murine and human neonates, the $\mathrm{cDC}$ compartment is smaller than that of adults ${ }^{9-11}$ and cDCs from both human and murine neonates express lower basal levels of major histocompatibility complex II (MHCII) and costimulatory molecules rendering them less potent at stimulating $\mathrm{T}$ cells ${ }^{12-15}$. The early life murine cDC compartment further exhibits an intrinsic bias to generate T-helper type 2 (Th2) immune responses due to delayed production of IL-12p70 16,17 . Such Th2 bias is also evident in cord blood cDCs, which exhibit reduced IL12 p70 production and upregulation of costimulatory molecules following pathogenic stimulation compared to $\mathrm{cDCs}$ from peripheral blood of adults ${ }^{13,14,18}$. However, expansion of $\mathrm{cDCs}$ in early life by administration of the DC growth factor fms tyrosine kinase 3 ligand (FLT3L) can improve innate and adaptive immune defense in mice ${ }^{19,20}$, indicating a potential of early life cDCs to initiate functional immune responses.

The cDC compartment is composed of developmentally distinct subsets with unique functions in immunity ${ }^{5,6,21}$. cDC1 are potent cross-presenters and activators of $\mathrm{CD}^{+} \mathrm{T}$ cells and promote Th1 differentiation through the production of interleukin12 (IL-12) and interferon- $\gamma(\text { IFN- } \gamma)^{22-24}$. In contrast, cDC2 are considered more potent activators of $\mathrm{CD} 4^{+} \mathrm{T}$ cells and inducers of Th2, Th17, and T-follicular helper cell differentiation ${ }^{25-29}$. The neonatal cDC compartment in mice is dominated by $\mathrm{cDC1}$, whereas $\mathrm{CDC} 2$ constitute the main $\mathrm{CDC}$ subtype in most adult organs $9,10,30,31$. Considering the predominant role of $\mathrm{CDC1}$ in producing IL- 12 and IFN- $\gamma$ in adults ${ }^{23,24}$, it is unlikely that subset distribution can account for the observed Th2 bias of the cDC compartment in early life and in most human tissues the relative frequency of $\mathrm{cDC} 1$ and $\mathrm{cDC} 2$ remains stable throughout life ${ }^{15}$. These data suggest that an additional layer of age-dependent regulation influences $\mathrm{cDC}$ function. This is highlighted by the fact that neonatal $\mathrm{cDC1}$ are refractory to IFN- $\alpha$ signaling, produce less IL-12 but more IL-10 than their adult counterparts and have a reduced capacity to activate $\mathrm{CD} 4{ }^{+} \mathrm{T}$ cells and select epitopes for presentation to $\mathrm{CD}^{+} \mathrm{T}$ cells during viral infection $9,16,17,32,33$.

Few studies have investigated $\mathrm{CDC} 2$ in early life. In neonatal mouse spleen, $\mathrm{CD}^{-} \mathrm{cDCs}$ show lower production of IFN- $\gamma$ and reduced activation of alloreactive $\mathrm{T}$ cells than their adult counterparts ${ }^{9}$. Although CD8 expression does not reliably distinguish cDC1 and $\mathrm{cDC} 2$ in neonatal spleen ${ }^{17,34}$, these data suggest a reduced ability of neonatal cDC2 to activate T cells. Similarly, cDC2 in neonatal lung express lower costimulatory molecules than adult $\mathrm{cDC}^{32,35-37}$, although they can promote Th2mediated allergy and induce some $\mathrm{CD}^{+}{ }^{+} \mathrm{T}$-cell proliferation when infected with respiratory syncytial virus ${ }^{30,32,38}$. These data indicate that in early life, $\mathrm{cDC} 2$ have the potential to activate $\mathrm{T}$ cells in some circumstances, raising the question whether this capacity could be harnessed in a broader sense, for instance to initiate T-cell responses in the spleen, which is a major site for antibody production ${ }^{39}$.

The first blood and immune cells arise from extra-embryonic yolk sac progenitors and for some cell types, such as macrophages or mast cells, yolk sac-derived cells can persist in tissues for extended periods of time after birth ${ }^{40-42}$. cDCs first arise during embryogenesis in mice and humans, when they are thought to critically contribute to fetomaternal tolerance $e^{9,10,40,43}$. However, the origins of $\mathrm{cDCs}$ in early life have not been investigated. In adults, cDCs develop downstream of hematopoietic stem cells (HSCs) from a fraction of myeloid bone marrow progenitors capable of generating plasmacytoid DCs (pDCs) and cDCs that has been termed common DC progenitor (CDP) ${ }^{44-47}$. Within CDPs in mice, expression of the C-type lectin receptor DNGR-1 (encoded by the Clec $9 a$ gene) distinguishes cDC-restricted progenitors $^{48}$. CDPs further differentiate into pre-cDCs, which continue to express DNGR-148, exit the bone marrow and terminally differentiate into $\mathrm{cDC}$ subtypes in peripheral organs and in response to environmental cues ${ }^{49}$. The Clec $9 a$ promoter is also active in $\mathrm{CDC} 1$ and to a lower extent on pDCs but it is not active in $\mathrm{cDC} 2$ and other lymphoid or myeloid cells $s^{48,50-52}$. By crossing mice expressing CRE-recombinase under the Clec9a promoter to Rosalox-stop-lox -yellow fluorescent protein (YFP) or Rosalox-stop-lox_TOMATO mice, we have generated mice that faithfully track cells belonging to the $\mathrm{CDC}$ lineage in steady state and under inflammatory conditions ${ }^{48,53,54}$. Using these mice, we have found that $\mathrm{CDC} 2$ in adult spleen are predominantly derived from $\mathrm{CDP} /$ pre-cDC $^{48,53,54}$, which is consistent with other studies $^{55,56}$.

Here we set out to investigate the differences between $\mathrm{CDC} 2$ in early and adult life and clarify the reasons underlying agedependent functional regulation of $\mathrm{cDC} 2$. We reveal that $\mathrm{cDC} 2$, analogous to other lymphoid and myeloid cell types, develop in waves. CDC2 arising from distinct hematopoietic sources in early life are phenotypically and transcriptionally similar, and functionally capable to induce T-cell responses. cDC2 in early and adult life, however, have a distinct ability to sense pathogens, produce cytokines and induce T-cell differentiation that is transcriptionally imprinted by distinct cytokine signaling in early and adult life. Exploiting the unique aspects of $\mathrm{cDC} 2$ in early life may thus provide an efficient means to boost vaccination efficacy and protective immunity.

\section{Results}

Early-life cDC2 exhibit ontogenetic diversity. To investigate phenotype and origin of $\mathrm{cDCs}$ in early life, we first profiled these cells in Clec $9 a^{\text {cre/+}}$ Rosa ${ }^{T O M}$ mice. In this context, we defined the neonatal period as the first 10 days after birth ${ }^{57}$. In the steady-

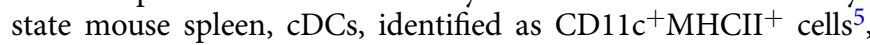
could be found as early as embryonic day 16 (E16, Fig. 1a, b and Supplementary Fig. 1). The frequency of $\mathrm{CD}_{11 \mathrm{c}^{+}} \mathrm{MHCII}^{+}$cells increased steadily with age and reached adult levels at around 4 weeks of age (Fig. 1a, b and Supplementary Fig. 1), confirming results of previous studies ${ }^{9,10}$. CD11 $\mathrm{c}^{+} \mathrm{MCHII}^{+}$cells could further be divided into $\mathrm{CD} 24^{+}$and $\mathrm{CD} 11 \mathrm{~b}^{+}$cells ${ }^{5}$. CD $24^{+} \mathrm{cDCs}$ include $\mathrm{XCR}-1^{+}$BATF3-dependent $\mathrm{CDC} 1$, as well a subset of non-canonical BATF3-independent $\mathrm{CD}^{+}{ }^{+} \mathrm{cDCs}$ that expresses CD172a and CX3CR1 but lacks XCR-1 (Fig. 1a) ${ }^{58-60}$. As expected, $\mathrm{CD} 24^{+}$cDCs dominated the splenic $\mathrm{CDC}$ compartment in early life but became less frequent with age, whereas the proportion of $\mathrm{CD}_{11 b^{+}} \mathrm{cDC} 2$ increased with age ${ }^{9}$ (Fig. 1c). Notably, $\mathrm{XCR}-1^{+} \mathrm{cDC} 1$ were the more frequent cell type within $\mathrm{CD} 24^{+}$ cells at most ages examined, although in 2-day-old and adult mice non-canonical $\mathrm{CD}^{+} \mathrm{cDC}$ and $\mathrm{cDC} 1$ were present at equal 
a PND7 spleen Clec9a ${ }^{\text {cre }}$ Rosa ${ }^{\text {TOM }}$
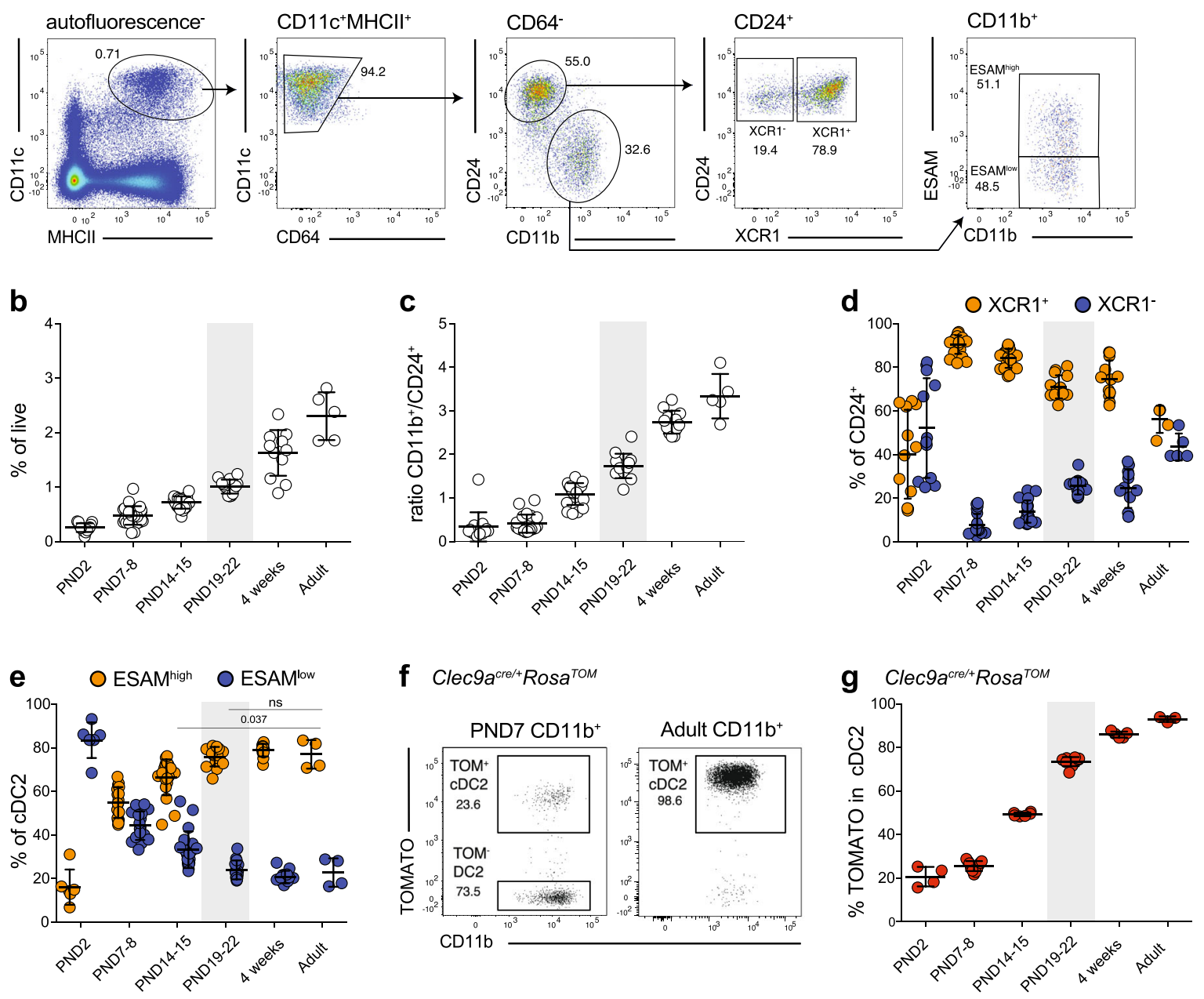

f Clec $9 a^{\text {cre/+}}$ Rosa $a^{\text {TOM }}$
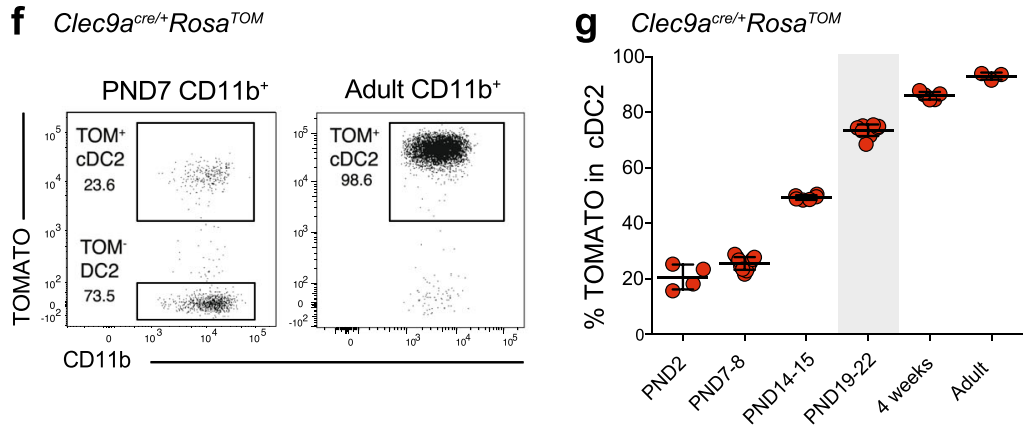

h Bone marrow
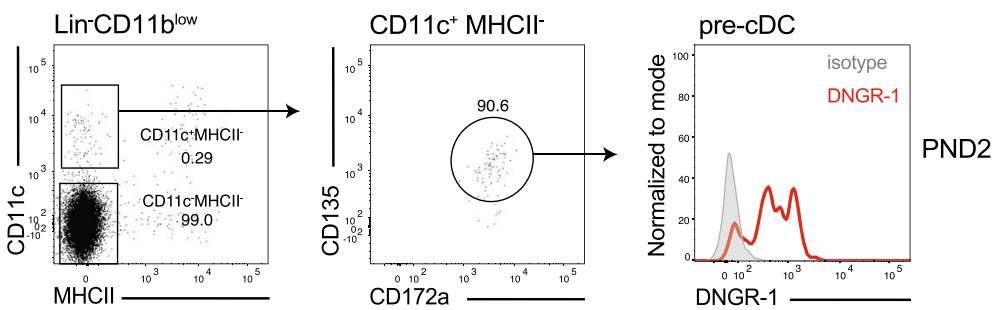

i Spleen

Lin-CD11 bow

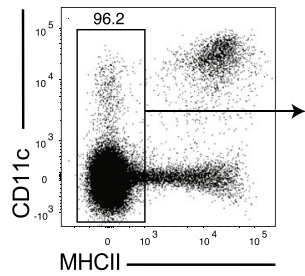

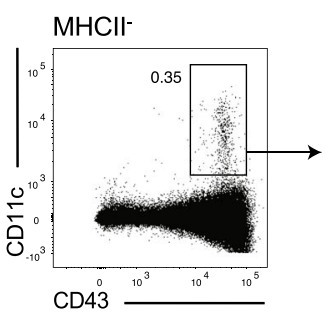

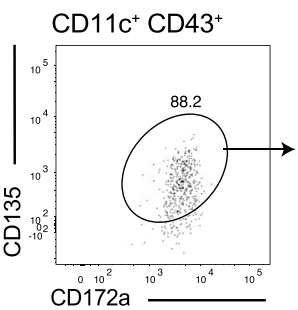

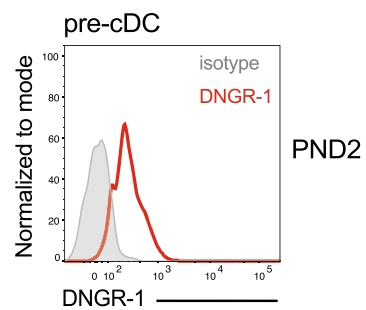

proportions (Fig. 1d). In the spleen, $\mathrm{CD} 11 \mathrm{~b}^{+} \mathrm{cDC} 2$ can be divided into NOTCH2- and RUNX3-dependent ESAM ${ }^{\text {high }}$ cDC2 and ESAM $^{\text {low }} c D C 2$, which develop independent of these transcription factors ${ }^{61-63}$ (Fig. 1a and Supplementary Fig. 1A, B). Notably, $\mathrm{ESAM}^{\text {high }}$ cells were less frequent within the $\mathrm{CDC} 2$ compartment of neonatal compared to adult mice; however, the proportion of ESAM $^{\text {high }}$ cells within the $\mathrm{cDC} 2$ compartment reached adult levels between 2 and 3 weeks of age (Fig. 1e and Supplementary Fig. 1A, B), which coincides with the organization of the splenic architecture.

We next assessed Clec9a-expression history with age by profiling TOMATO expression in splenic leukocytes from Clec $9 a^{\text {cre/ }+}$ RosaTOM mice. cDC2 lack DNGR-1 expression and therefore TOMATO labeling in this population is a true indicator 
Fig. 1 Developmental heterogeneity of early life cDC2. a-e Spleens from Clec $9 a^{\text {cre } /+}{ }^{R o s} a^{T O M}$ and $C l e c 9 a^{c r e} / c r e R o s a^{T O M}$ mice of the indicated ages were analyzed by flow cytometry. a Single live autofluorescence-negative cells were gated and cDCs identified as $\mathrm{CD} 11 \mathrm{c}^{+} \mathrm{MHClI}{ }^{+} \mathrm{CD} 64^{-}$cells. $\mathrm{cDCs}$ were further divided into $\mathrm{CD}_{24}+$ and $\mathrm{CD} 11 \mathrm{~b}^{+}$cells, and analyzed for XCR-1 and ESAM expression, respectively. $\mathbf{b}$ Frequency of $\mathrm{CD} 11 \mathrm{c}^{+} \mathrm{MHCII}{ }^{+} \mathrm{cDC}$ s in total splenocytes ( $n=13$, PND2; $n=25$, PND7-8; $n=20$, PND14-15; $n=14$, PND19-22; $n=12,4$ weeks; $n=5$, adult). c Ratio of CD11b ${ }^{+}$to CD24+ cells within $\mathrm{CD}_{11} \mathrm{C}^{+} \mathrm{MHCl}{ }^{+} \mathrm{cDCs}\left(n=13, \mathrm{PND} 2 ; n=21, \mathrm{PND} 7-8 ; n=20\right.$, PND14-15; $n=14$, PND19-22; $n=12,4$ weeks; $n=5$, adult). $\mathbf{d}$ The percentage of XCR-1 ${ }^{+}$ and XCR-1 ${ }^{-}$cells within CD24+ ${ }^{c D C 1}$ is shown $(n=12$, PND2; $n=21, \mathrm{PND} 7-8 ; n=20$, PND14-15; $n=14, \mathrm{PND} 19-22 ; n=12,4$ weeks; $n=5$, adult). e The percentage of ESAM high and ESAM low cells within $\mathrm{CD}^{\text {lib }}{ }^{+} \mathrm{cDC} 2$ is shown $(n=6$, PND2; $n=11$, PND7-8; $n=18$, PND14-15; $n=14$, PND19-22; $n=11$, 4 weeks; $n=4$, adult). f Representative flow cytometry gating for TOMATO expression in splenic cDC2 from 1-week-old and adult Clec9acre/+RosaTOM mice. $\mathbf{g}$ The frequency of TOMATO ${ }^{+}$cells within splenic CD11b ${ }^{+} \mathrm{cDC2}$ of Clec9acre/+Rosa ${ }^{\text {TOM }}$ mice with age $(n=4$, PND2; $n=11$, PND7-8; $n=6$, PND14-15; $n=10$, PND19-22; $n=5,4$ weeks; $n=3$, adult). Each dot represents one mouse, horizontal bars represent mean, error bars represent SD, gray rectangles indicate weaning. ns: not significant. Statistical analysis was performed using two-tailed $t$-test. $\mathbf{h}$, i Bone marrow (h) and spleen (i) from 2-dayold wild-type mice were analyzed by flow cytometry. Lin ${ }^{-}$(CD3, B220, NK1.1, CD4, CD8 $\alpha$, TER119) cells were gated, pre-cDCs were identified as indicated and stained with anti-DNGR-1 (red) or isotype-matched control antibodies (gray). Source data are provided as a Source Data file.

of cell origin ${ }^{48}$. Consistent with our previous observations and their CDP origin ${ }^{5,48,54-56}$, cDC2 from adult spleen showed nearcomplete labeling with TOMATO in Clec $9 a^{\text {cre/+}}$ Rosa $^{T O M}$ mice $(93 \pm 1.28 \%)$. Notably, in neonatal mice TOMATO labeling in cDC2 was strongly reduced $(20.6 \pm 4.48 \%)$, indicating ontogenetic heterogeneity. The frequency of $\mathrm{TOMATO}^{+}$cells within $\mathrm{CDC} 2$ increased with age until adult labeling was reached at around 4 weeks of age $(86 \pm 1.4 \%$; Fig. 1f, g).

We have previously shown that increased CRE levels (in homozygous $\mathrm{Clec} 9 a^{\text {cre }}$ mice) leads to markedly increased labeling of DC precursors and differentiated cDCs, because a fraction of precursors 'escapes" labeling in a stochastic fashion ${ }^{48}$. In addition, the choice of fate reporter can influence labeling efficiency due to differences in the distance between the loxP sites $^{64}$. To exclude that reduced labeling of neonatal cDC2 was an artifact of the specific fate reporter used or due to "progenitor escape" in mice heterozygous for cre, we analyzed homozygous Clec $9 a^{\text {cre/cre }}$ RosaTOM mice and Clec $9 a^{\text {cre/cre }}$ Rosa ${ }^{\text {YFP }}$ mice. In both models, a relative lack of $\mathrm{Clec} 9 \mathrm{a}^{\text {cre }}$-mediated fate labeling in neonatal cDC2 was observed (Supplementary Fig. 1C, D). Importantly, TOMATO labeling did not correlate with either of the two cDC2 subsets, as ESAM ${ }^{\text {high }}$ or ESAM ${ }^{\text {low }}$ cells showed similar labeling frequency at all ages examined (Supplementary Fig. 1E). Comparable to observations in adult mice ${ }^{48,54}, \mathrm{Clec} 9 a^{\text {cre }}$ mediated TOMATO labeling in young mice remained restricted

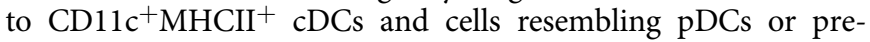
cDCs based on low CD11c and MHCII expression (Supplementary Fig. 1F, G).

As most of our work on DC ontogeny stems from studies in adult mice, we next confirmed that DNGR-1-expressing cDC progenitors were present in early life bone marrow and spleen. Cells resembling macrophage dendritic cell progenitors (MDPs) (lineage (lin) $\left.{ }^{-} \quad \mathrm{CD}_{11 c^{-}} \mathrm{MHCII}^{-} \mathrm{CD} 11 \mathrm{~b}^{\text {low }} \mathrm{CD} 115^{+} \mathrm{CD} 135^{+} \mathrm{CD} 117^{\text {high }}\right)$, CDPs (lin ${ }^{-} \mathrm{CD} 11 \mathrm{c}^{-} \mathrm{MHCII}-\mathrm{CD} 11 \mathrm{~b}^{\text {low }} \mathrm{CD} 115^{+} \mathrm{CD} 135^{+} \mathrm{CD} 117^{\text {low }}$ ), and pre-cDCs (lin ${ }^{-} \mathrm{MHCII}^{-} \mathrm{CD} 11 \mathrm{~b}^{\text {low }} \mathrm{CD} 11 \mathrm{c}^{+} \mathrm{CD} 135^{+} \mathrm{CD} 172 \mathrm{a}^{\mathrm{int}}$ ) could be found in bone marrow from neonatal mice (Supplementary Fig. 2A, B). Notably, putative MDPs were more frequent, whereas CDP and pre-cDC-like cells were less frequent in neonatal compared to adult bone marrow (Supplementary Fig. 2B). Importantly, pre-cDC-like cells in bone marrow from 2-day- and 1-week-old mice uniformly expressed DNGR-1 (Fig. 1h and Supplementary Fig. 2C). Accordingly, TOMATO was detected in CDPs and pre-cDCs, but not MDPs or common lymphoid progenitors (CLPs) of 1- and 2-week-old Clec $9 a^{\text {cre/cre }}$ RosaTOM mice, as defined phenotypically (Supplementary Fig. 2E). These data confirm that Clec $9 a$-driven CRE was active in DC precursors in early life. Importantly, pre-cDCs from 1- and 2-week-old mice labeled with TOMATO to a similar extent as their counterparts from adult mice, although labeling at 1 week of age had not completely reached adult levels (Supplementary Fig. 2E;
$81.15 \pm 2.77 \%$ PND7, $94.67 \pm 1.72 \% 2$ weeks, $93.61 \pm 2.93 \%$ adult $)$ Pre-cDC-like cells with unimodal DNGR-1 expression were also found in spleen from 2-day- and 1-week-old mice (Fig. 1i and Supplementary Fig. 2D), and labeled with TOMATO at similar levels as their bone marrow counterparts (Supplementary Fig. 2E, F), indicating that CRE-mediated labeling of pre-cDCs completes in bone marrow. Actively cycling progenitor cells can escape labeling because of a time lag between CRE protein synthesis and DNA recombination ${ }^{45,48,49}$. If $\mathrm{cDC} 2$ in neonates escaped labeling because of such rapid transition through their precursor stage, we would expect higher labeling in differentiated $\mathrm{cDC} 2$ than in their immediate progenitors. However, splenic pre-cDC labeled with TOMATO to a larger extent than differentiated cDC2 from the same mice at one and 2 weeks of age (Supplementary Fig. 2F). This is in contrast to adult mice, where labeling of splenic cDC2 and pre-cDCs was similar (Supplementary Fig. 2f). To further exclude the possibility that $\mathrm{CDC} 2$ in early life lack detectable TOMATO, because they have had insufficient time to accumulate enough fluorescent protein, we sorted $\mathrm{TOMATO}^{+}$

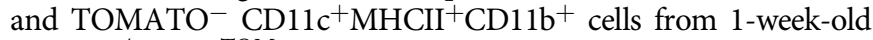
Clec $9 a^{\text {cre/cre }}$ Rosa $a^{\text {TOM }}$ mice and cultured them in the presence of the DC survival factors FLT3L and Granulocyte-macrophage colonystimulating factor (GM-CSF). After $24 \mathrm{~h}$, TOMATO- ${ }^{-}$cells had remained $\mathrm{TOMATO}^{-}$, supporting the notion that these cells arise independently of $\mathrm{Clec} 9 \mathrm{a}$-expressing progenitors (Supplementary Fig. 2G). Thus, cells resembling bona fide Clec $9 a$-expressing cDC progenitors exist in early life and $C l e c 9 a^{c r e}$ mice can be used to trace cDCs in early life.

Fate mapping reveals a lymphoid contribution to $\mathrm{CDC} 2$ in early life. To address the origin of $\mathrm{CDC} 2$ in early life, we first crossed Clec $9 a^{\text {cre/cre }}$ Rosa ${ }^{Y F P}$ mice to mice lacking the growth factor FLT3L, which is required for the development of all DCs ${ }^{65}$. In 2-week-old Clec $9 a^{\text {cre/cre }}$ Rosa ${ }^{Y F P}$ Flt $3 l^{-1-}$ mice, both $\mathrm{cDC1}$ and cDC2 were strongly reduced (Fig. 2a). Thus, early-life cDC2 require FLT3L for their development, independent of whether they arise from $\mathrm{Clec} 9 \mathrm{a}$-expressing progenitors or not. Hematopoiesis begins before birth and, in mice, yolk sac progenitors contribute to the generation of lymphoid and myeloid immune cells $41,42,66,67$. To assess the contribution of yolk sac erythromyeloid progenitors to the $\mathrm{CDC} 2$ compartment in early life, we treated pregnant Csf1rMer-iCre-Mer Rosa ${ }^{Y F P}$ dams at E8.5 with $4 \mathrm{OH}$-tamoxifen ${ }^{41,67}$ and analyzed spleens from offspring mice at E18.5, as well as 2 and 4 weeks after birth. Importantly, neither $\mathrm{CD} 24^{+}$nor $\mathrm{CD}_{11 \mathrm{~b}}{ }^{+} \mathrm{cDCs}$ labeled with YFP at any ages examined, when compared to liver Kupffer cells and splenic macrophages, which served as positive controls (Fig. $2 \mathrm{~b}$ and Supplementary Fig. 3A). The transcription factor $\mathrm{c}-\mathrm{Myb}$ is dispensable for yolk sac hematopoiesis but essential for the 
a PND14 spleen
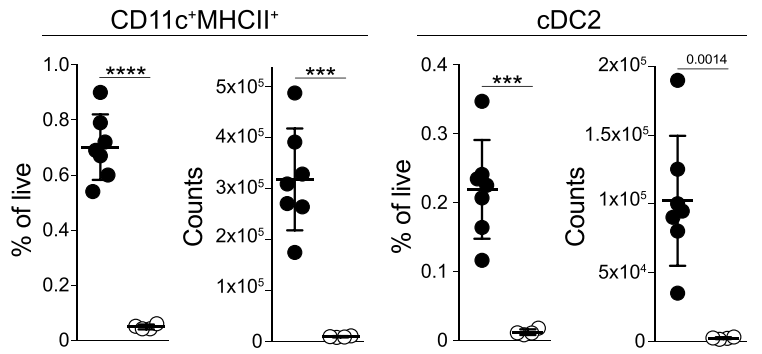

$\mathrm{cDC} 2$

- $\mathrm{Flt} \mathrm{H}^{+++} \mathrm{Clec} 9 \mathrm{a}^{\text {cre/cre }} \mathrm{Rosa}^{\mathrm{YFP}}$

O Flt3 ${ }^{-}$-Clec $9 a^{\text {cre/cre }}$ Rosa ${ }^{\text {YFP }}$

b Csf1 $r^{\text {Mericre-MerRosaYFP }}$

C Spleen
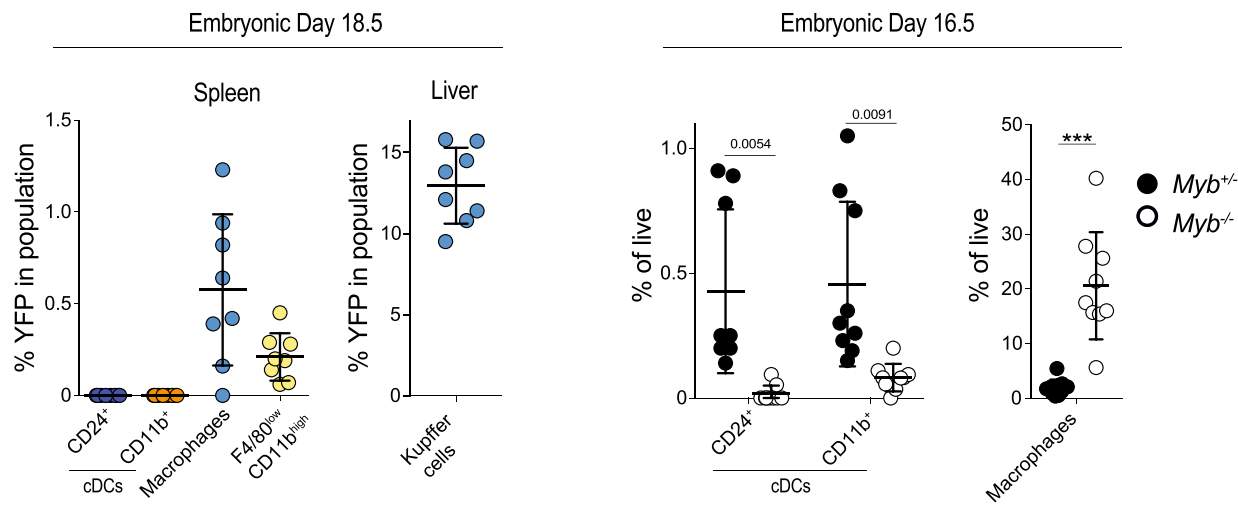

d Rag1" ${ }^{\text {cre }}$ Rosa $^{\text {YFP }}$
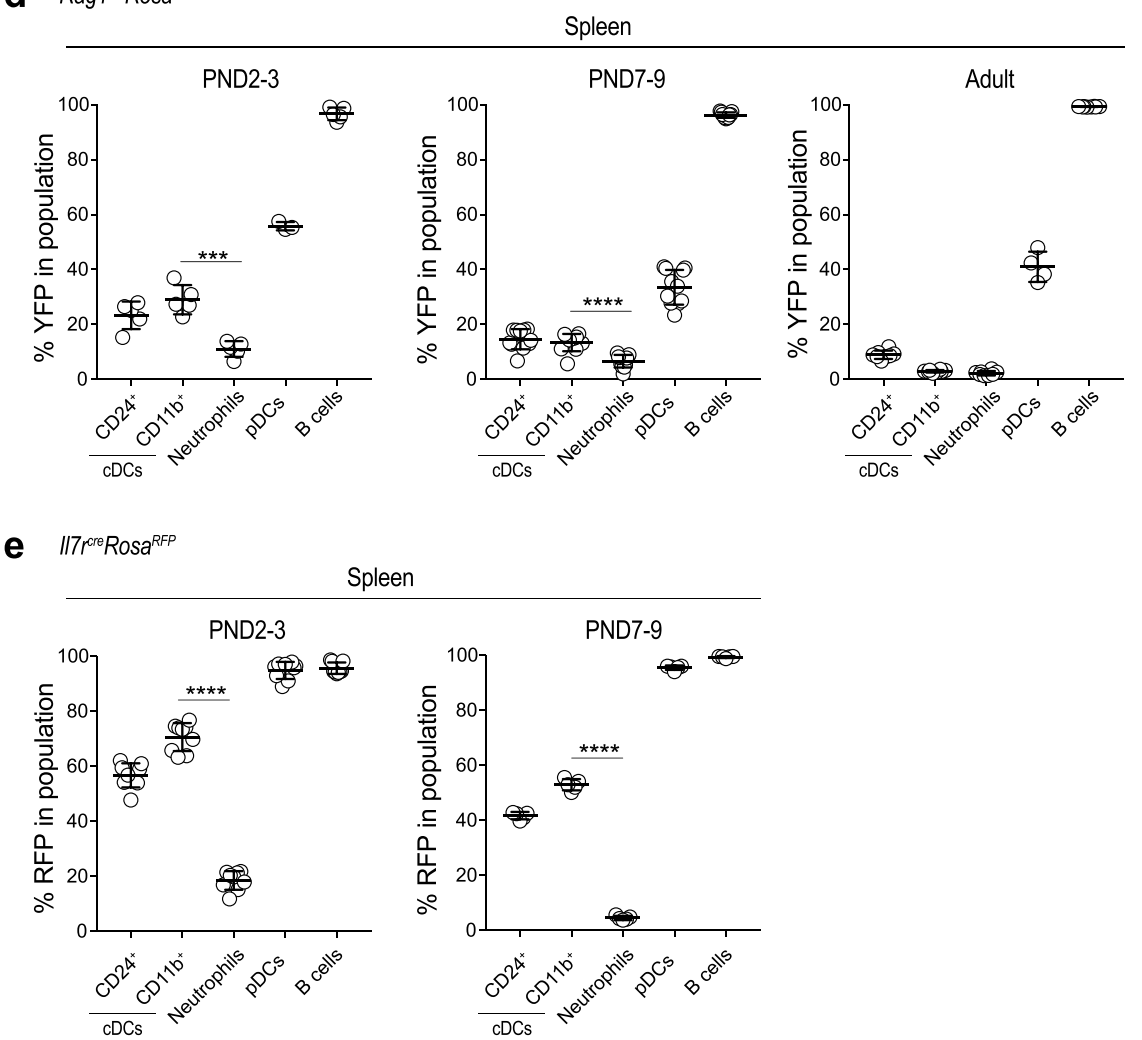

development of definitive HSCs ${ }^{68}$. Myb-deficient mice are embryonically lethal but survive until E16.5. At this time CD24 ${ }^{+}$ and $\mathrm{CD} 11 \mathrm{~b}^{+} \mathrm{cDCs}$, but not splenic macrophages, were reduced in spleens from $M y b^{-l-}$ compared to littermate control embryos

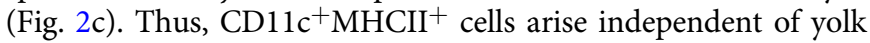

sac-derived erythromyeloid progenitors and in late embryogenesis require $\mathrm{c}-\mathrm{Myb}$ for their development, suggesting that they arise from definitive hematopoiesis.

CLPs can generate cDC-like cells in adoptive transfer ${ }^{69-73}$ and we have shown that lymphopoiesis contributes to $\mathrm{CDC}$ generation 
Fig. 2 Fate mapping reveals a lymphoid contribution to cDC2 in early life. a Spleens from 2-week-old Flt3l-/-Clec9a ${ }^{\text {cre } / \text { cre } R o s a^{Y F P}}(n=7)$ and

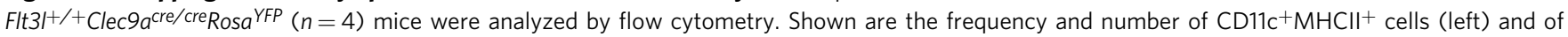
cDC2 (middle). b Csf1rMer-iCre-Mer dams were mated with male RosaYFP mice and injected with 4OH-tamoxifen on E8.5. Spleen and liver from offspring mice were analyzed by flow cytometry on E18.5. The percentage of YFP + cells in the indicated populations is plotted $(n=8)$. c Spleens from Myb ${ }^{-/-}$and $\mathrm{Myb}^{+/-}$littermate control mice were analyzed on E16.5. The frequency of the indicated populations was calculated and plotted $(n=9)$. d The percentage of YFP ${ }^{+}$cells within the respective populations in spleen from Rag ${ }^{1}$ re Rosa ${ }^{\text {YFP }}$ mice at the indicated ages $(n=5$, PND2-3; $n=11$ PND7-9; $n=8$ adult; $n=3$

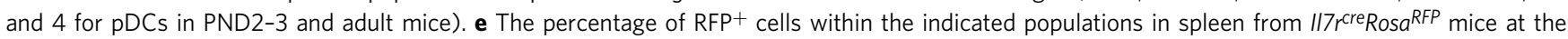
indicated ages ( $n=9$, PND2-3; $n=5$, PND7-9). Each dot represents one mouse, horizontal bars represent mean, error bars represent SD. ${ }^{\star \star \star} p<0.001$, ${ }^{\star \star \star \star} p<0.0001$. Statistical analysis in $\mathbf{a}, \mathbf{c}-\mathbf{e}$ was performed using two-tailed $t$-test. Source data are provided as a Source Data file.

when myeloid cDC progenitors are impaired ${ }^{74}$. When cultured in vitro with FLT3L CLPs from Clec $9 a^{\text {cre } /+}$ Rosa $^{T O M}$ mice gave

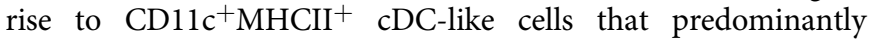
resembled cDC1. However, few cDC2-like cells were also generated. These remained TOMATO negative, suggesting that CLP can generate $\mathrm{TOM}^{-} \mathrm{cDC}^{-}$(Supplementary Fig. 3B). Expression of recombination-activating gene-1 is first detected in CLPs and required for the development of $\mathrm{B}$ and $\mathrm{T}$ cells by promoting somatic rearrangements of antigen receptor genes ${ }^{75}$. Therefore, we profiled YFP labeling of splenic leukocytes in neonatal Rag1 ${ }^{\text {cre }}$ Rosa ${ }^{Y F P}$ mice at 2-3 and 7-9 days after birth, as well as in adulthood. As lineage decisions are stochastic, fate mapping with constitutive Cre is not absolute and should be considered at the population level and in the context of positive and negative control populations. Although B cells exhibited near-complete labeling with YFP at all ages examined (Fig. 2d), labeling in neutrophils $(11 \pm 2.86 \%$ PND2-3, $6.63 \pm 2.32 \%$ PND7-9, $2.27 \pm 0.82 \%$ adults, Fig. 2d) and bone marrow erythroid cells $(5.32 \pm 1.88 \%$ PND2-3, $1.87 \pm 0.8 \%$ PND7-9) (Supplementary Fig. 3C), which served as negative controls, was low as expected ${ }^{66}$. Notably, in 2- to 3-day- and 7- to 9-day-old Rag1 ${ }^{\text {cre }}$ Rosa $^{\text {YFP }}$ mice cDC2 labeled with YFP at $29 \pm 5.30 \%$ and $13.43 \pm 3.16 \%$, respectively (Fig. 2d and Supplementary Fig. 3C), whereas in cDC2 from adult spleen Rag1 ${ }^{\text {cre }}$-mediated YFP labeling did not exceed labeling of negative control populations (Fig. 2d and Supplementary Fig. 3C). Importantly, YFP labeling was comparable between ESAM ${ }^{\text {high }}(16.15 \pm 1.01 \%)$ and ESAMlow $(15.21 \pm 1.07 \%)$ cDC2 in 7 - to 9-day-old mice (Supplementary Fig. 3D), again supporting similar early life heterogeneity in both subsets. Of note, $\mathrm{CD} 24^{+} \mathrm{cDC} 1$ showed greater evidence of Rag1 ${ }^{\text {cre }}$ expression history compared to $\mathrm{cDC} 2$ in neonatal and adult mice (Fig. 2 d). IL-7 receptor ( $I l 7 r$ )-cre mice have been used to demonstrate that lymphoid progenitors do not contribute to cDCs in adult mice ${ }^{76}$. We therefore used these mice as independent model to map the fate of lymphoid-restricted progenitors. Importantly, cDC2 from 2-day- and 1-week-old $I l 7 r^{\text {cre }}$ Rosa ${ }^{R F P}$ mice labeled strongly with RFP, although labeling was lower in cDC2 from 1 week compared to 2-day-old mice (Fig. 2e).

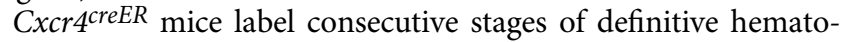
poiesis in embryonic and adult mice, while not labeling yolk sac progenitors ${ }^{77}$. We therefore pulsed Cxcr4 $4^{\text {creER }}$ Rosa $^{m T m G}$ mice with tamoxifen at E12.5, reasoning that fetal liver HSCs would be labeled, allowing us to assess their contribution to splenic DCs. At E18.5, microglia, which served as negative control, exhibited no green fluorescent protein (GFP) labeling, as expected ${ }^{77}$. In contrast, we observed labeling of monocytes and macrophages in E18.5 spleen, consistent with their descendance from fetal liver HSCs (Supplementary Fig. 3E). Importantly, cDCs labeled with GFP to a similar extent, supporting the notion that fetal liverresident progenitors contribute to $\mathrm{CDC} 2$ in early life (Supplementary Fig. 3E).

Thus, fate mapping indicates a lymphoid contribution to the steady-state CDC2 pool in early life, but not adulthood. Coupled to the observation that $\mathrm{cDC} 2$ acquire $C l e c 9 a^{\text {cre }}$ expression history with age, these data suggest that $\mathrm{cDC} 2$ development is regulated in waves, with fetal liver-resident lymphoid progenitors contributing early but being gradually replaced with age by bona fide cDCs arising from Clec $9 a$-expressing progenitors. Henceforth, we will refer to $\mathrm{CD}_{11 \mathrm{c}^{+}} \mathrm{MHCII}^{+} \mathrm{CD} 11 \mathrm{~b}^{+}$cells from Clec $9 a^{\text {cre }}$ Rosa $a^{T O M}$ mice that lack TOMATO expression as $\mathrm{TOM}^{-}$DC2 (Fig. 1f).

$\mathrm{TOM}^{+} \mathrm{CDC} 2$ and $\mathrm{TOM}^{-} \mathrm{DC} 2$ in early life are phenotypically similar. Phenotypic analysis revealed no obvious differences in the expression of the prototypical cDC2 markers CLEC4A4, CD172a, CD26, ESAM, or CD4 on $\mathrm{TOM}^{+} \mathrm{cDC}^{2}$ and $\mathrm{TOM}^{-}$

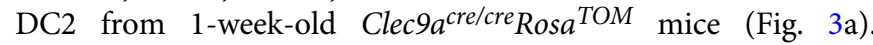
Expression of MHCII and the costimulatory molecule CD80 were also similar between $\mathrm{TOM}^{+}$and $\mathrm{TOM}^{-}$cells (Fig. 3a). Using cytospin analyses we found cells with the typical dendritic morphology of cDCs, as well as cells with round morphology and little cytoplasm within $\mathrm{TOM}^{+} \mathrm{cDC}^{2}$ and $\mathrm{TOM}^{-}$DC2 (Supplementary Fig. $3 \mathrm{~F}$ ). $\mathrm{TOM}^{+} \mathrm{cDC}_{2}$ and $\mathrm{TOM}^{-} \mathrm{DC} 2$ in spleens from 1 -week-old mice were located in the developing white pulp and in close proximity to $\mathrm{CD}^{+} \mathrm{T}$ cells (Fig. $3 \mathrm{~b}$ ). Thus, Clec $9 a$-negative progenitors generate $\mathrm{cDC} 2$-like cells with similar phenotype and tissue localization to bona fide $\mathrm{cDC} 2$ arising from $\mathrm{Clec} 9 \mathrm{a}$ expressing progenitors.

$\mathrm{TOM}^{+}$cDC2 and $\mathrm{TOM}^{-} \mathrm{DC} 2$ in early life are transcriptionally identical. Although environment strongly impacts cell identity, myeloid and lymphoid cell types arising from distinct hematopoietic sources at specified times during development can differ transcriptionally and functionally ${ }^{42,78-82}$. To address if ontogeny transcriptionally imprints $\mathrm{cDC} 2$, we compared the gene expression profile of $\mathrm{TOM}^{+} \mathrm{cDC}^{2}$ and $\mathrm{TOM}^{-} \mathrm{DC} 2$ from 1 -week-old Clec $9 a^{\text {cre/cre }}$ Rosa $a^{\text {TOM }}$ mice to that of $\mathrm{TOM}^{+} \mathrm{cDC} 2$ from adult mice. We used homozygous Clec $9 a^{\text {cre/cre }}$ Rosa $^{T O M}$ mice to ensure highest penetrance $C l e c 9 a^{\text {cre }}$ and the 1-week time point, because ontogenetic heterogeneity was prominent enough to sort sufficient cells of both populations (Supplementary Fig. 1C), although ESAM $^{\text {high }}$ to ESAM ${ }^{\text {low }}$ subset distribution at this age was still slightly lower than in adult mice (Fig. 1e). In principal component analysis (PCA) $\mathrm{TOM}^{+} \mathrm{cDC} 2$ and $\mathrm{TOM}^{-} \mathrm{DC} 2$ from 1 -weekold mice segregated away from adult $\mathrm{TOM}^{+} \mathrm{cDC} 2$, identifying age as a major contributor to variation (Fig. 4a). Principle component 2 allowed some segregation between $\mathrm{TOM}^{+} \mathrm{cDC} 2$ from $\mathrm{TOM}^{-}$DC2 from young mice, indicating differences in gene expression correlating with differential ontogeny (Fig. 4a). Using unsupervised hierarchical k-means clustering of differentially expressed genes we defined 14 clusters with distinct expression characteristics (Supplementary Fig. 4A). Of these, most clusters identified differences between cells from young and adult mice independent of Clec9acre expression history (Supplementary Fig. 4A), again highlighting that the biggest differences in gene expression are related to age. Clusters 8 and 14 identified genes 

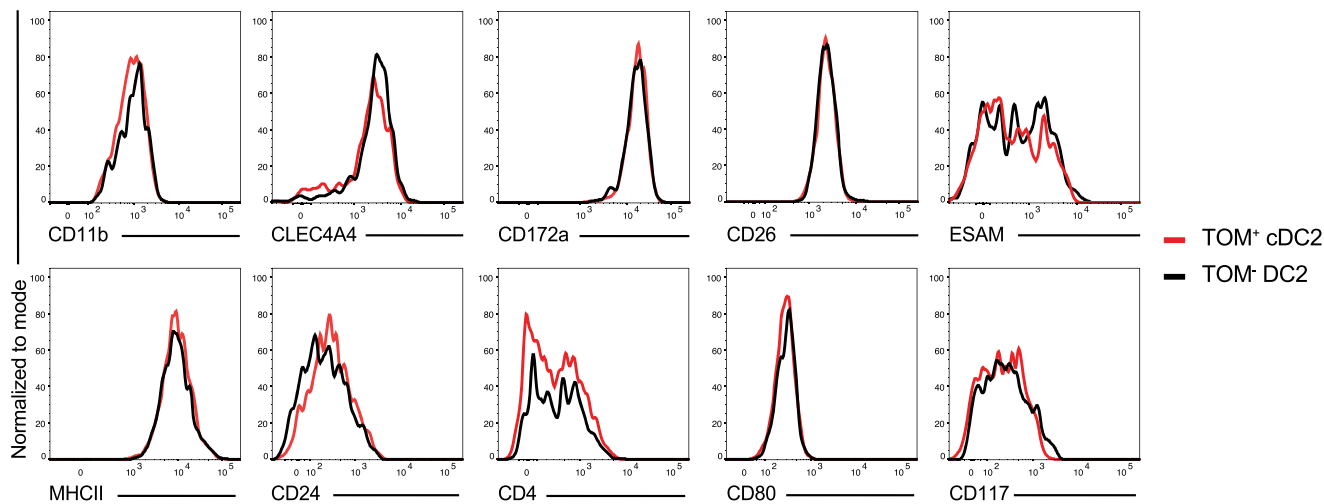

CD117

b PND8 spleen Clec9a ${ }^{\text {crelcre }}$ RosaTom
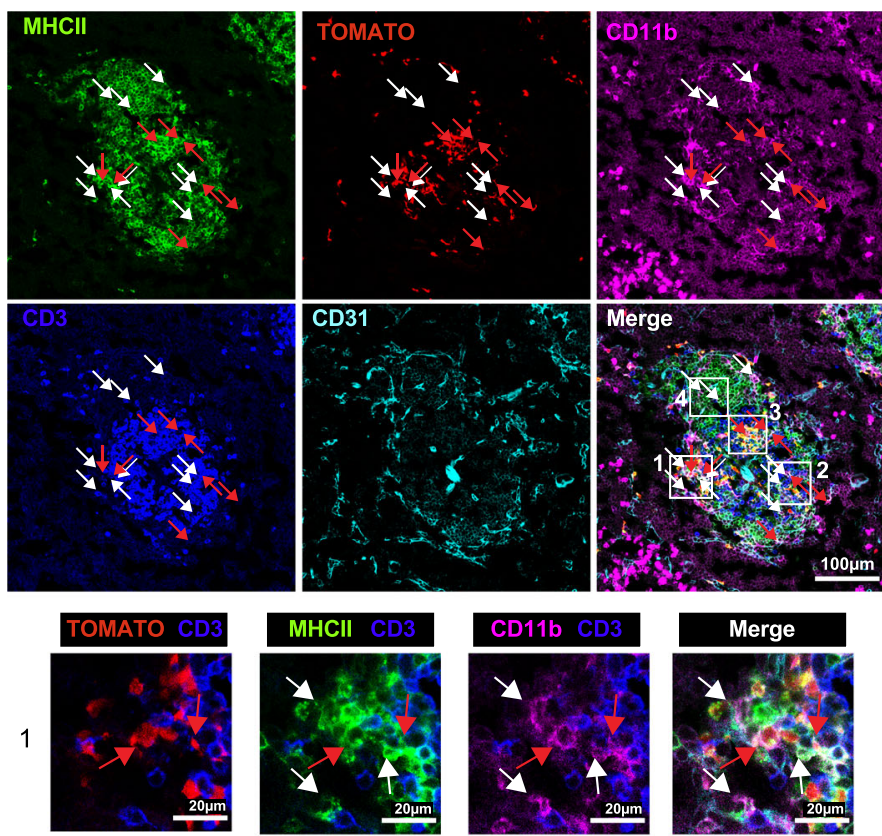

2
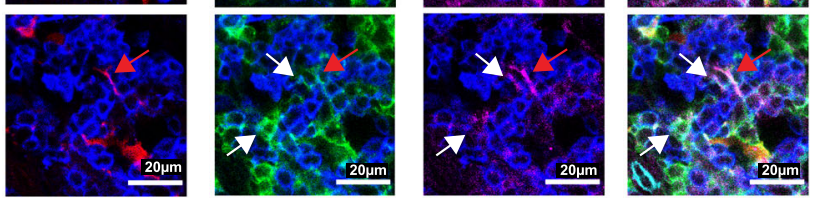

3
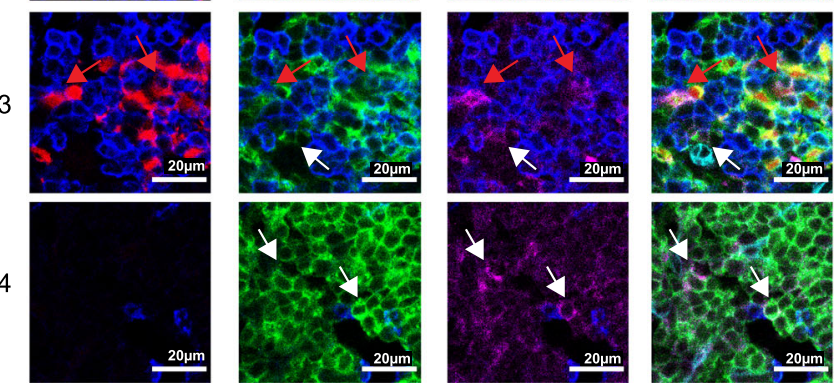

$\mathrm{TOM}^{+} \mathrm{CDC2}$

TOM DC2

Fig. 3 TOM- DC2 phenotypically resemble TOM ${ }^{+}$cDC2. a TOM ${ }^{+}{ }^{-} D C 2$ and TOM - DC2 from 1-week-old Clec9acre/cre RosaTOM mice were analyzed for expression of the indicated surface markers. Data are representative of at least two independent experiments with four to seven mice. $\mathbf{b}$ Spleens from PND8 Clec9acre/cre RosaTOM mice were analyzed for expression of CD31 (cyan), CD3 (blue), MHCII (green), TOMATO (red), and CD11b (magenta) by microscopy. Numbered inset squares were magnified on the bottom panels TOM ${ }^{+} \mathrm{cDC} 2$ (red arrows) or TOM ${ }^{-} \mathrm{DC}^{2}$ (white arrows) were identified. Data are representative of two independent experiments with three biological replicates. 
a

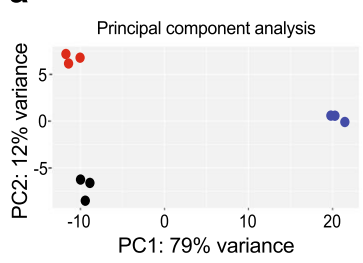

Cell type

$\mathrm{TOM}^{+} \mathrm{cDC} 2$

TOM- DC2 young

TOM ${ }^{+} \mathrm{CDC} 2$ adult
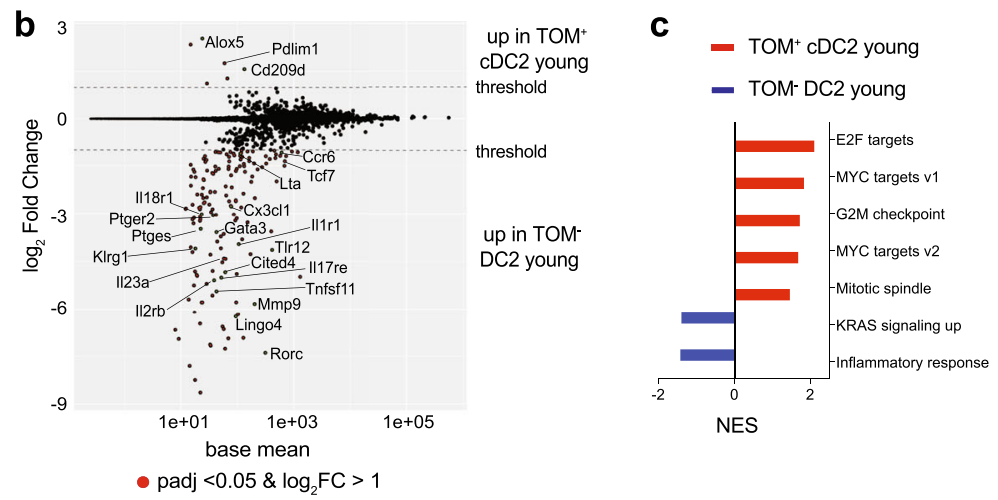

d PND8 spleen $\mathrm{Clec} 9 a^{\text {cre/cre }} \mathrm{Rosa}^{\text {TOM }}$

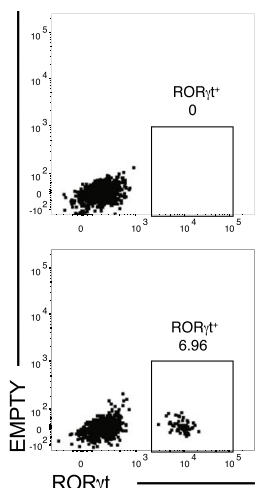

ROR $\gamma \mathrm{t}$

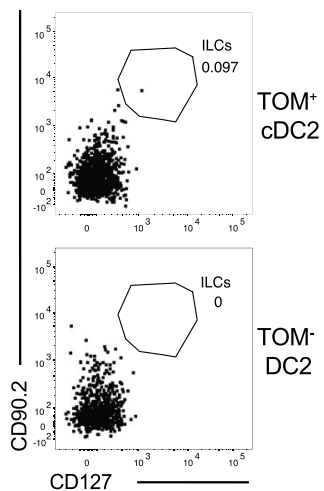

$\operatorname{CD} 127 \quad 10^{3} \quad 10^{4} \quad 10^{5}$
Spleen $\mathrm{Clec} 9 a^{\text {cre/cre }} \mathrm{Rosa}^{\mathrm{TOM}}$

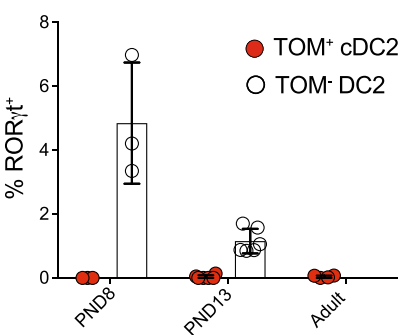

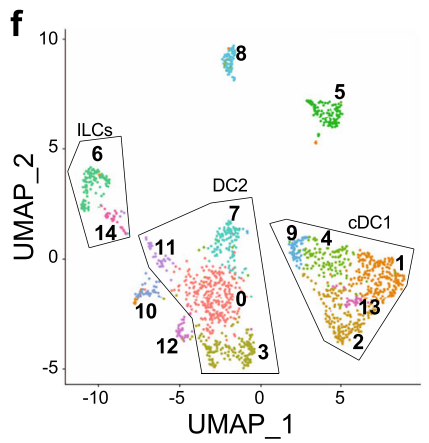

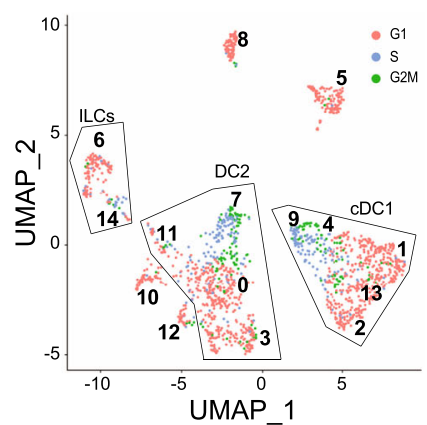

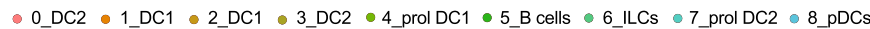
- 9_prol DC1 -10_Migratory DC • 11_unknown -12_nc CD8 cDC • 13_DC1 -14_prol ILCs
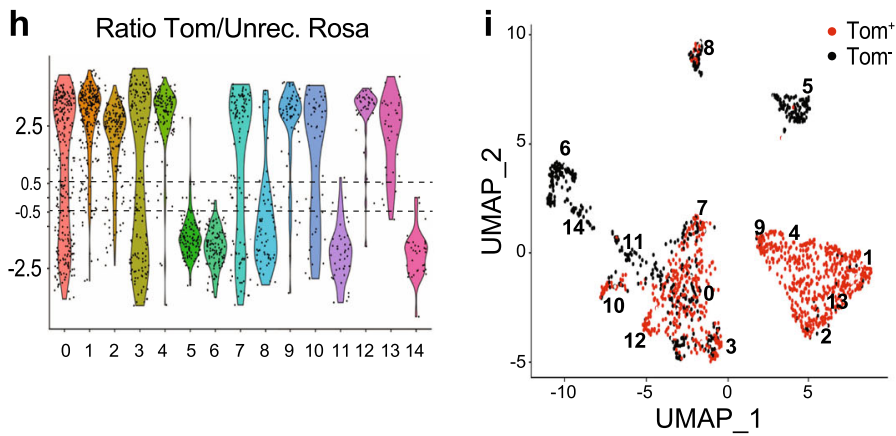

g

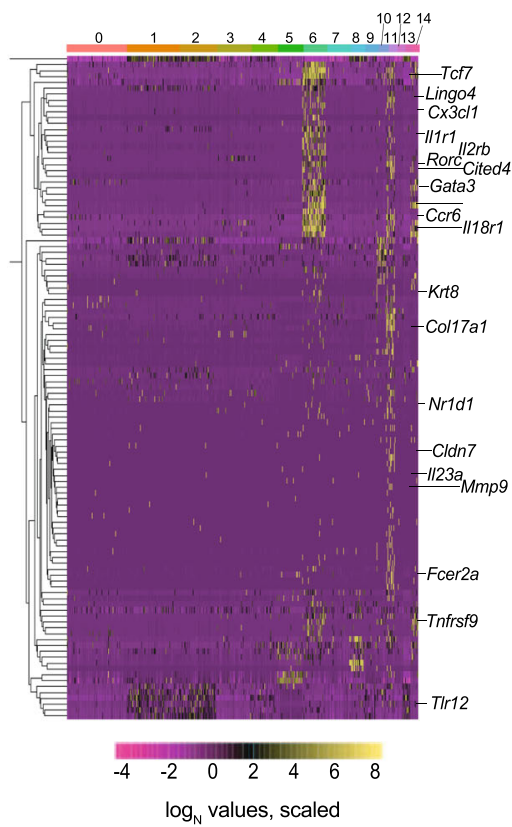

with distinct expression characteristics in $\mathrm{TOM}^{-} \mathrm{DC} 2$ compared to $\mathrm{TOM}^{+} \mathrm{cDC} 2$ from young and adult mice (Supplementary Fig. 4A), identifying putative variation caused by ontogeny.

Pairwise comparison of $\mathrm{TOM}^{+} \mathrm{cDC} 2$ and $\mathrm{TOM}^{-} \mathrm{DC} 2$ from young mice identified 167 differentially expressed genes $\left(\log _{2}\right.$ fold change $\left(\log _{2} \mathrm{FC}\right)>1$, adjusted $p$-value (padj) $\left.<0.05\right)($ Fig. $4 \mathrm{~b}$ and Supplementary Data 1). In this comparison, $\mathrm{TOM}^{+} \mathrm{CDC} 2$ showed

an enrichment of cell cycle genes (Fig. 4c), possibly reflecting the fact that these cells expand in number and gradually replace $\mathrm{TOM}^{-}$DC2 with age. Most notable, several genes implicated in the biology of innate lymphoid cells (ILCs), such as Rorc, Tcf7, Il18r1, Ccr6, Lingo4, and Lta, showed higher expression in TOM ${ }^{-}$ DC2 than $\mathrm{TOM}^{+}$cDC2 (Fig. 4b). Using flow cytometry, we detected a fraction of ROR $\gamma t$-expressing cells in $\mathrm{TOM}^{-} \mathrm{DC} 2$ but 
Fig. 4 TOM $^{+}$cDC2 and TOM - DC2 in early life are transcriptionally identical. a-c TOM- DC2 and TOM ${ }^{+} \mathrm{CDC}^{-}$from 8-day-old and TOM ${ }^{+} \mathrm{cDC}^{-}$from adult Clec9a ${ }^{\text {cre/cre }}$ Rosa $^{\text {TOM }}$ mice were sorted and analyzed by mRNA sequencing. a Principal component analysis (PCA) of the top 500 most variable genes across all samples. Dots represent biological replicates. b Pairwise comparison of TOM ${ }^{+} \mathrm{CDC}_{2}$ and $\mathrm{TOM}^{-} \mathrm{DC2}$ from 8-day-old mice. c Normalized

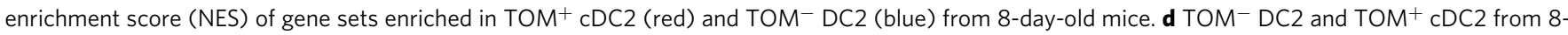
day-old Clec9a $a^{\text {cre/cre }}$ Rosa $^{T O M}$ mice were analyzed by flow cytometry for ROR $\mathrm{t}$, CD90.2, and CD127 expression. Data are representative of three biological replicates. e The percentage of ROR $\gamma \mathrm{t}^{+}$cells within TOM ${ }^{+} \mathrm{cDC} 2$ and TOM- DC2 in Clec9acre/cre RosaTOM mice at the indicated ages is shown ( $n=3$, PND8; $n=6$, PND13; $n=4$, adult). Each dot represents one mouse, horizontal bars represent mean, error bars represent SD. f, $\mathbf{g}$ CD19- MHCII+ cells from spleen of 9-day-old Clec9a cre/cre RosaTOM mice were sorted after gating out F4/80high macrophages and subjected to scRNA-Seq. $\mathbf{f}$ UMAP display of 1788 cells analyzed by unsupervised graph-based clustering with Seurat algorithm to indicate cluster identity (left) and cell cycle status (right) within clusters. g Heatmap displaying expression of genes enriched in TOM-DC2 compared to TOM ${ }^{+}$cDC2 in bulk mRNA sequencing (Fig. 4b) among scRNA-Seq clusters. $\mathbf{h}$, $\mathbf{i}$ The ratio of normalized Tomato reads per cell to normalized reads per cell of the predicted transcript of the unrecombined ROSA locus was calculated $(\mathbf{h})$ and cells with a ratio $>0.5$ were identified as Tom ${ }^{+}$, whereas cells with a ratio $<-0.5$ were identified as $\mathrm{Tom}^{-}$. $\mathbf{i} \mathrm{Tom}^{+}$and $\mathrm{Tom}^{-}$cells visualized on the UMAP display. Source data are provided as a Source Data file.

not in $\mathrm{TOM}^{+}$cDC2 from 1-week-old Clec $9 a^{\text {cre/cre }}$ Rosa ${ }^{\text {TOM }}$ mice (Fig. 4d, E). These cells lacked the canonical ILC markers CD127 and $\mathrm{CD} 90^{83-85}$ and expressed typical cDC2 markers, including CD11c, MHCII, CD172a, CLEC4A4, ESAM and CD26, unlike ILCs $\left(\right.$ lin $^{-} \mathrm{CD} 11 \mathrm{~b}^{-} \mathrm{CD} 90^{+} \mathrm{CD} 127^{+}$), which are $\mathrm{CD} 11 \mathrm{c}$ negative (Supplementary Fig. 4B, C). Notably, the frequency of ROR $\gamma \mathrm{t}^{+}$ cells within the $\mathrm{TOM}^{-}$DC2 population decreased with age and ROR $\gamma \mathrm{t}^{+}$cells were not found in the adult cDC2 pool (Fig. 4e), raising the possibility that these $\mathrm{ROR} \gamma \mathrm{t}^{+}$cells may constitute a unique population of DC2 that is transiently present in early life and disappears with age.

To address this, we next performed droplet-based single-cell RNA-sequencing (scRNA-seq). We sort-purified splenic $\mathrm{MHCII}^{+}$ cells from 9-day-old Clec9a $a^{\text {cre/cre }}$ Rosa $^{T O M}$ mice, after excluding CD19 ${ }^{+} \mathrm{B}$ cells and F4/80high macrophages (Supplementary Fig. 5A). Using this approach, we expected to identify all main DC subsets, including $\mathrm{CDC} 1$, non-canonical CD8 ${ }^{+} \mathrm{cDCs}, \mathrm{TOM}^{+}$ $\mathrm{cDC}^{2}$, and $\mathrm{TOM}^{-} \mathrm{DC} 2$ and CD11 ${ }^{\text {low }} \mathrm{MHCII}^{\text {low }} \mathrm{pDCs}$, as well as a fraction of ROR $\gamma \mathrm{t}$-expressing type 3 ILCs that expresses MHCII but lacks CD11c (Supplementary Figs. 4B and 5a). Unsupervised graph-based clustering identified 15 clusters as visualized by dimensionality reduction using Uniform Manifold Approximation and Projection (UMAP) (Fig. 4f) ${ }^{86,87}$. We identified some proliferating cells (being in G2M and S phase) in all clusters, but excluded clusters $4,7,9$, and 14 from comparative analyses, as they consisted predominately of proliferating cells (Fig. 4f). The identity of each cluster was determined using the top differentially expressed genes in combination with a priori knowledge about signature genes of $\mathrm{cDCs}$ and other immune cells (Supplementary Fig. 5B-E). Cluster 5 identified a contamination with Cd19-expressing B cells (Supplementary Fig. 5B), indicating a possible sort impurity or a discord between RNA and protein expression $^{88}$. cDC1 were partitioned across 5 clusters $(1,2,4,9$, and 13) based on expression of Xcrl, Cd24a, Irf8, and Tlr3 (Supplementary Fig. 5B, C). We further added the sequence of cre as inserted in the Clec $9 a$ locus ${ }^{48,89}$ into the reference transcriptome and found cre expression exclusively in clusters $1,2,4,9$, and 13 , consistent with Clec9a expression in early life $\mathrm{cDC} 1{ }^{17}$. Cluster 8 constituted Siglech and Ccr 9 expressing pDCs and clusters 6 and 14 showed high expression of Rorc, Rora, Il7r, Il18r1, and Tox, identifying them as ILC $3 \mathrm{~s}^{83,84}$. Cluster 12 resembled E2-2-dependent non-canonical $\mathrm{CD}^{+}{ }^{+} \mathrm{cDCs}$ based on Cx3cr1, Cd24a, Sirpa (CD172a), and Tcf4 (encoding for E2-2) expression $^{58,60}$ (Supplementary Fig. 5B, C). cDC2 were spread across clusters 0,3 , and 7 based on expression of Sirpa, Itgam, Irf4, and published signature genes ${ }^{90}$ (Supplementary Fig. 5B, D). Notably, cluster 3 more closely resembled ESAM ${ }^{\text {low }}$, whereas cluster 0 resembled ESAM ${ }^{\text {high }} \mathrm{CDC}^{59}$ (Supplementary Fig. 5F). In addition, we identified cluster 10 as cells resembling migratory $\mathrm{cDCs}^{90}$ (Supplementary Fig. 5E). We were not able to assign a clear identity to cluster 11 , although this cluster showed expression of core $\mathrm{CDC} 2$ and $\mathrm{ESAM}^{\text {high }}$ cDC2 signature genes (Supplementary Fig. 5D, F). Notably, Rorc was found among the genes characteristic for cluster 11 and this population showed an enrichment of genes with higher expression in $\mathrm{TOM}^{-} \mathrm{DC} 2$ in the pairwise comparison of $\mathrm{TOM}^{+} \mathrm{CDC}^{+}$ and $\mathrm{TOM}^{-}$DC2 in bulk RNA-seq (Fig. $4 \mathrm{~g}$ and Supplementary Fig. 5B).

We next identified $\mathrm{TOM}^{+}{ }^{+} \mathrm{CDC} 2$ and $\mathrm{TOM}^{-} \mathrm{DC} 2$ by adding the sequence of Tomato and the predicted transcript of the unrecombined Rosa locus into the reference transcriptome ${ }^{91}$. Forming the ratio of normalized Tomato reads per cell to normalized reads per cell of the predicted transcript of the unrecombined Rosa locus (ratio Tom/unrec. Rosa) clearly separated B cells (cluster 5) and CDC1 (clusters 1, 2, 4, 9, and 13), which served as negative and positive controls for Tomato expression, respectively (Fig. 4h). Accordingly, we set a threshold and identified $\mathrm{Tom}^{-}$(ratio Tom/unrec. Rosa $\left.<-0.5\right)$ and $\mathrm{Tom}^{+}$ cells (ratio Tom/unrec. Rosa $>0.5$, Fig. 4h). Tom ${ }^{+}$and Tom $^{-}$cells distributed evenly within the UMAP of cDC2 clusters 0,3 , and 7 (Fig. 4i), and pairwise comparison of $\mathrm{Tom}^{+}$and $\mathrm{Tom}^{-}$cells within clusters 0 and 3 revealed few differences in gene expression, indicating that these cells are transcriptionally similar (Supplementary Data 2). Notably, cells within cluster 11 were predominantly $\mathrm{Tom}^{-}$, again indicating that this cluster corresponds to ROR $\gamma$ t-expressing TOM $^{-}$DC2 (Fig. 4i).

In adults, $\mathrm{cDC} 2$ can be divided into T-bet expressing $\mathrm{cDC} 2 \mathrm{~A}$ and T-bet-negative cDC2B, putatively controlled by ROR $\gamma t$ and $\mathrm{C} / \mathrm{EBPa}^{92}$. This division appeared to hold up in early life as cluster 0 showed an enrichment of $\mathrm{T}$-bet ${ }^{+}{ }$cDC2A signature genes (Supplementary Fig. 5G), whereas cluster 3 more closely resembled T-bet ${ }^{-}$cDC2B (Supplementary Fig. 5G). Interestingly, cells in cluster 11 did not correspond to T-bet ${ }^{-} \mathrm{cDC} 2 \mathrm{~B}$ but more

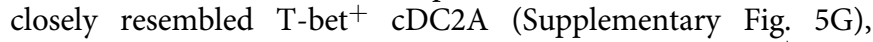
consistent with the high expression of ESAM on ROR $\gamma \mathrm{t}^{+} \mathrm{DC} 2$ (Supplementary Fig. 4C). To gain insights into a putative developmental hierarchy between Rorc-expressing cluster 11, cDC2 (clusters 0, 3, and 7), and ILC3 (clusters 6 and 14), we applied Palantir algorithm ${ }^{93}$. Setting the starting point within cluster 11 identified two terminal states, one in ILC cluster 14 and one in cDC2 cluster 0 (Supplementary Fig. 5H). However, differentiation potential diminished quickly upon exit from cluster 11 and the branch probability that cells from cluster 11 reach the terminal states was low (Supplementary Fig. $5 \mathrm{H}$ ). Accordingly, fate mapping in $\operatorname{Rorc}^{\text {cre }} \operatorname{Ros}^{R F P}$ mice ${ }^{94}$ identified only few $\mathrm{RFP}^{+} \mathrm{cDC}_{2}$ in 2-week-old mice that included a fraction that also stained positive for ROR $\gamma t$ (Supplementary Fig. 5I). As $\mathrm{RFP}^{+}$cells were only a minor fraction of the total splenic DC2 compartment in young mice, $\mathrm{ROR} \mathrm{t}^{+}$cells are unlikely to act as progenitors for $\mathrm{TOM}^{-} \mathrm{DC} 2$ in early life. 
Thus, in concordance with fluorescence-activated cell sorting (FACS) analyses, scRNA-seq revealed that $\mathrm{cDC} 2$ in 1-week-old mice contain the two main $\mathrm{CDC} 2$ subtypes also found in adults, and that, despite their distinct origin, $\mathrm{TOM}^{+} \mathrm{cDC} 2$ and $\mathrm{TOM}^{-}$ DC2 distribute evenly across CDC2 clusters, indicating they constitute transcriptionally identical cells. Differences in gene expression between $\mathrm{TOM}^{+} \mathrm{CDC}^{\mathrm{C}}$ and $\mathrm{TOM}^{-} \mathrm{DC} 2$ from 1-weekold mice in bulk RNA-seq correlated to a unique Rorc-expressing cluster of cDC2 that transcriptionally closely resembles but is distinct from $\mathrm{ESAM}^{\text {high }} \mathrm{cDC} 2$ and present exclusively in early life.

Age defines the strongest differences in gene expression. Having established ontogeny as a minor contributor to transcriptional variation, we next focused on differences in gene expression caused by age. Pairwise comparison of $\mathrm{TOM}^{+} \mathrm{cDC} 2$ from 1week-old and adult mice identified 1490 differentially expressed genes $(\log 2 \mathrm{FC}>1, \operatorname{padj}<0.05)$ (Fig. 5a and Supplementary Data 3). $\mathrm{TOM}^{+} \mathrm{CDC}$ from 1-week-old mice showed an enrichment of genes involved in cell cycle (Fig. 5b), possibly reflecting increased homeostatic proliferation within the expanding DC pool. $\mathrm{TOM}^{+} \mathrm{cDC} 2$ from adults were enriched for genes implicated in the inflammatory response, which could indicate an increased level of activation or functional maturation of adult $\mathrm{CDC} 2^{15}$. Most notable was the identification of genes involved in signaling downstream of IFN- $\gamma$, tumor necrosis factor- $\alpha$ (TNF- $\alpha$ ), IL-2, and IFN- $\alpha$ (Fig. 5b) enriched in CDC2 from adult mice. As expression of receptors for these cytokines was comparable in 1-week-old and adult mice (Supplementary Data 3), these data suggested a distinct cytokine environment acting on $\mathrm{cDC} 2$ in spleen from neonatal and adult mice. We confirmed higher expression of PD-L1 (encoded by the Cd274 gene) and $\mathrm{CD} 38$ (Cd38), which are regulated by type I and II IFN signaling 95,96 , on $\mathrm{TOM}^{+}{ }^{\mathrm{CDC} 2}$ from adult compared to 2-weekold mice (Fig. 5c). Importantly, expression of these markers was reduced on CDC2 from adult Ifnar ${ }^{-1-}$ compared to wild-type control mice (Fig. 5d), supporting the notion that distinct cytokine environments act on splenic CDC2 in early and adult life and indicating that age-dependent differences in gene expression are at least in part caused by IFN- $\alpha$.

Among genes differentially expressed with age, we identified several pattern recognition receptors (PRRs) with higher expression in $\mathrm{TOM}^{+} \mathrm{cDC} 2$ from adults, including Clec7a (encoding for Dectin-1), Tlr7, and Tlr5 (Supplementary Fig. 6A). In contrast, expression of Clec4n (encoding for Dectin-2), Tlr4, and Tlr2 was higher in early life (Supplementary Fig. 6A), whereas expression of other PRRs, such as Tlr6, Tlr9, and Nod1 was comparable in cDC2 from 1-week-old and adult mice (Supplementary Fig. 6A). In line with previous observations in the lung ${ }^{32,35-37}, \mathrm{CDC} 2$ from adult mice showed higher expression of several costimulatory molecules, including Cd80, Cd40, Cd274 (encoding for PD-L1) and Tnfsf4 (encoding for OX40L) (Fig. 5a). Lower expression of costimulatory molecules could indicate a reduced ability of earlylife $\mathrm{CDC} 2$ to activate $\mathrm{T}$ cells but costimulatory signals also balance effector T-cell responses. Tnfsf 4 and $\mathrm{Cd} 274$ for instance can suppress IL-17A production in T cells $s^{97,98}$. Interestingly, adult CDC2 further showed higher expression of bone morphogenic protein 2 (Bmp2), which also suppresses IL-17A production from T cells ${ }^{99}$ (Supplementary Fig. 6B). On the contrary, TOM ${ }^{+}$cDC2 from 1-week-old mice showed higher levels of factors that promote Th17 and Treg differentiation, such as Lgals3, Il6ra, Lgals1, and Sema4a $a^{100-106}$ (Supplementary Fig. 6B). In line with age being the foremost contributor to transcriptional variation, expression of the aforementioned genes was similar between $\mathrm{TOM}^{+}{ }_{\mathrm{cDC}}$ and $\mathrm{TOM}^{-}$DC2 from 1-week-old mice. Taken together, these data suggest that distinct cytokine environments in early and adult life act on CDC2 to shape their transcriptional profile and ability to induce immune responses.

Early-life cDC2 induce distinct T-cell responses in vitro compared to adult-life cDC2. The above data suggested that CDC2 in early and adult life may differ in their ability to induce effector Tcell differentiation. To address this possibility in vitro, we sortpurified $\mathrm{TOM}^{+} \mathrm{cDC} 2$ and $\mathrm{TOM}^{-} \mathrm{DC} 2$ from young and $\mathrm{TOM}^{+}$ cDC2 from adult mice, and pulsed them with Ovalbumin (OVA) peptide 323-339 $\left(\mathrm{OVA}_{323-339}\right)$. cDC2 populations were sorted from two to 2.5-week-old mice, because at this age ESAM ${ }^{\text {high }}$ to ESAM $^{\text {low }}$ subset distribution had reached adult levels and ESAM $^{\text {high }}$ cells dominated the cDC2 compartment (Fig. 1e). Although DNGR-1 has no known function in DC development and is not expressed in $\mathrm{CDC}$, we used mice heterozygous for cre in functional assays, because $\mathrm{Clec} 9 a^{\text {cre/cre }}$ mice lack functional DNGR-1 ${ }^{48}$. Peptide pulsed DC2 populations were subsequently cultured with naive OT-II transgenic T cells from adult mice in the absence or presence of T-cell polarizing cytokines. Adult $\mathrm{T}$ cells were chosen as responders, because neonatal $\mathrm{T}$ cells exhibit an intrinsic Th2 bias $^{2}$. Notably, $\mathrm{TOM}^{+} \mathrm{cDC} 2$ and $\mathrm{TOM}^{-}$ DC2 from young mice and $\mathrm{TOM}^{+}{ }^{\mathrm{CDC} 2}$ from adult mice stimulated similar proliferation of naive $\mathrm{T}$ cells in all conditions tested (Fig. 5e, f and Supplementary Fig. 6C, D), indicating that adult CDC2 do not exhibit an increased level of activation in terms of their ability to stimulate $\mathrm{T}$ cells. Compared to adult $\mathrm{cDC} 2, \mathrm{TOM}^{+} \mathrm{cDC} 2$, and $\mathrm{TOM}^{-} \mathrm{DC} 2$ from young mice also induced similar effector differentiation of OT-II cells under nonpolarizing (Th0) and Th1 conditions, as assessed by IFN- $\gamma$ production (Fig. 5g and Supplementary Fig. 6D). We did not observe IL-4 production from T cells stimulated under Th0 conditions by intracellular staining but Th2 cytokine levels in culture supernatants from $T$ cells stimulated with $\mathrm{CDC} 2$ from young and adult mice were similar (Supplementary Fig. 6F). Thus, early life splenic cDC2 do not exhibit an intrinsic Th2 bias, which is in contrast to neonatal cDC2 from lung ${ }^{30}$. In line with higher expression of positive regulators of Th17 differentiation, $\mathrm{TOM}^{+}{ }^{\mathrm{CDC} 2}$ and $\mathrm{TOM}^{-}$DC2 from young mice induced twofold higher IL-17A production from $\mathrm{T}$ cells under Th17 conditions than $\mathrm{CDC} 2$ from adult mice (Fig. 5f, g). Similarly, under Treg conditions more OTII $\mathrm{T}$ cells were positive for Foxp3 when stimulated with DC populations from young mice (Fig. 5f, g). Thus, despite exhibiting increased expression of proliferation related genes (Fig. 5b), cDC2 from young mice induce similar proliferation of $\mathrm{T}$ cells as their adult counterparts, whereas inducing higher Th17 and Treg differentiation, indicating qualitative, rather than quantitative differences in the ability to polarize $\mathrm{T}$ cells.

As ESAM $^{\text {high }}$ and ESAM ${ }^{\text {low }}$ cDC2 have different transcriptional programs and may stimulate different types of T-cell responses ${ }^{62}$, we next addressed whether both subsets have different functions with age. We therefore sorted ESAM ${ }^{\text {high }}$ and ESAM $^{\text {low }} \mathrm{TOM}^{+} \mathrm{cDC} 2$ from 2-week-old and adult mice and assessed their ability to stimulate Th17 and Treg differentiation as above. ESAM ${ }^{\text {high }}$ and ESAM ${ }^{\text {low }} \mathrm{CDC} 2$ from young mice induced higher Th17 differentiation than their counterparts from adult mice (Fig. 5h). Similarly, ESAM ${ }^{\text {high }} \mathrm{cDC} 2$ from young mice induced higher Treg differentiation than their adult counterparts, whereas ESAM ${ }^{\text {low }}$ cDC2 from young and adult mice induced similar Treg differentiation (Fig. 5h). Thus, functional differences between early and adult life exist for ESAM ${ }^{\text {high }}$ and ESAM $^{\text {low }} \mathrm{cDC} 2$, although there appears to be some level of subset specific functional regulation. As ESAM ${ }^{\text {high }} \mathrm{TOM}^{-}$DC2 contain a unique fraction ROR $\gamma \mathrm{t}$-expressing cells of unknown function (1.15 $\pm 0.38 \%$, Fig. 4e), we next crossed Rorc-eGFP mice 

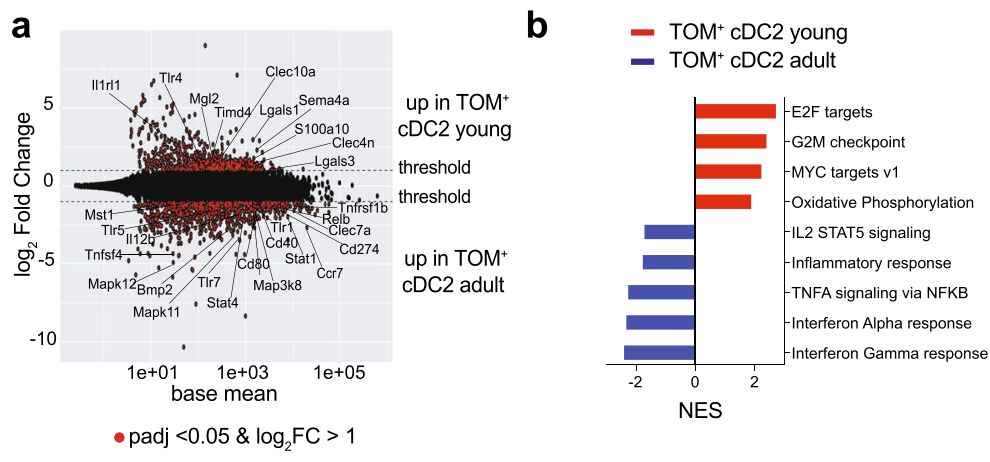

C $\mathrm{TOM}^{+} \mathrm{CDC} 2$ young $\bigcirc \mathrm{TOM}^{+} \mathrm{CDC} 2$ adult
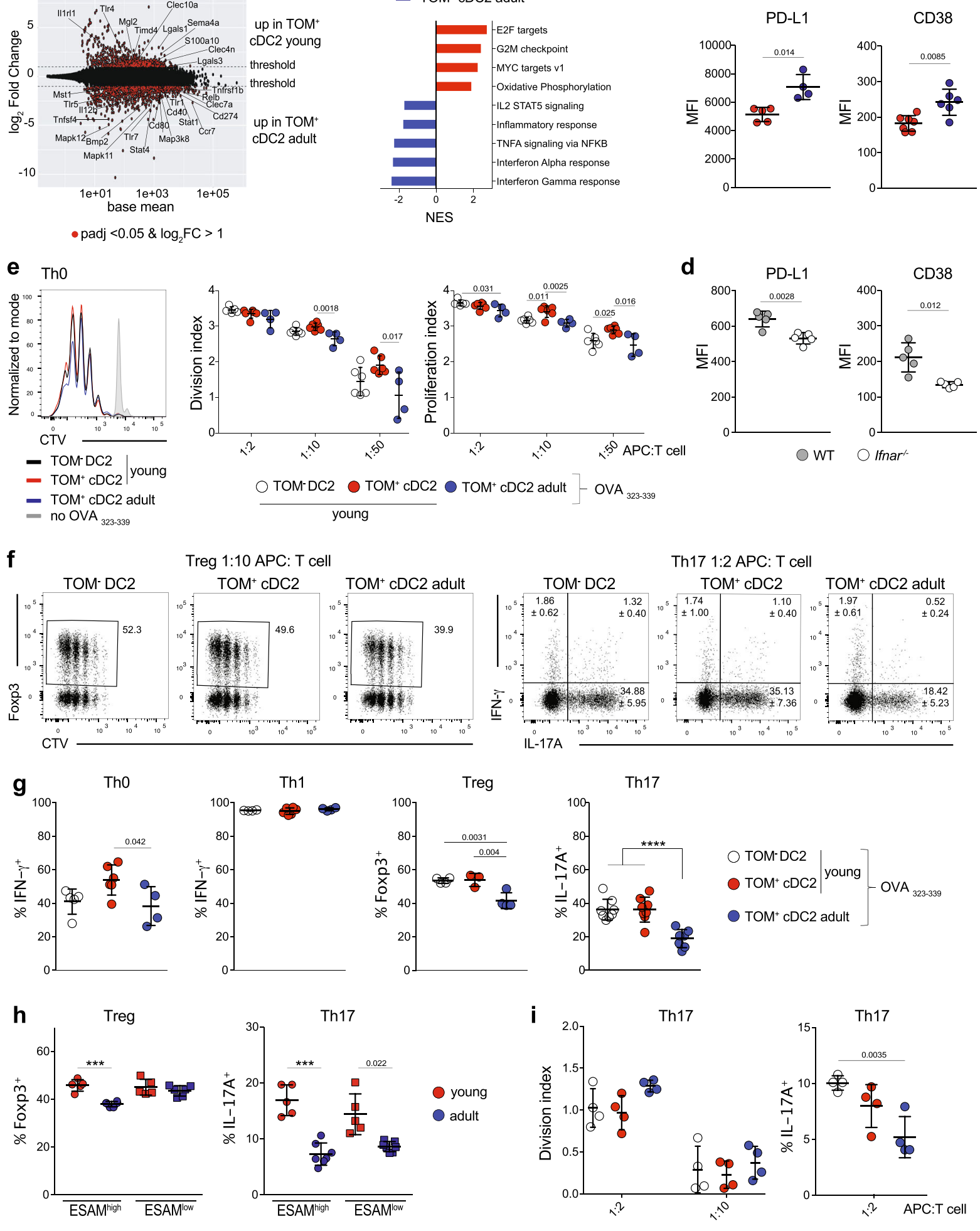

TOM-DC2 $\bigcirc \mathrm{TOM}^{+} \mathrm{CDC} 2 \bigcirc \mathrm{TOM}^{+} \mathrm{CDC} 2$ adult

to Clec $9 a^{\text {cre/ }}+$ Rosa $^{\text {TOM }}$ mice. We then sorted $\mathrm{ESAM}^{\text {high }} \mathrm{TOM}^{+}$ CDC2 and ESAM ${ }^{\text {high }}$ TOM $^{-}$DC2 from 2-week-old Rorc ${ }^{e G F P} C l e-$ $c 9 a^{c r e /+}$ RosaTOM mice, whereas excluding $\mathrm{GFP}^{+}$cells and compared their ability to promote Th17 and Treg differentiation. Importantly, despite excluding ROR $\mathrm{t}^{+}$cells $\mathrm{ESAM}^{\text {high }} \mathrm{TOM}^{+}$ CDC2 and ESAM ${ }^{\text {high }} \mathrm{TOM}^{-}{ }^{-} \mathrm{DC} 2$ had similar ability to induce Th17 and Treg differentiation (Supplementary Fig. 6G), confirming that the presence ROR $\gamma \mathrm{t}^{+}$cells does not influence the ability of $\mathrm{TOM}^{-} \mathrm{cDC} 2$ to induce T-cell differentiation.

To determine whether early-life cDC2 are also capable of antigen uptake and processing, we first cultured $\mathrm{TOM}^{+} \mathrm{CDC} 2$ and $\mathrm{TOM}^{-} \mathrm{DC} 2$ from 2-week-old and $\mathrm{TOM}^{+} \mathrm{cDC} 2$ from adult Clec $9 a^{\text {crel }}+$ RosaTom mice with fluorescently labeled latex beads in vitro for $2 \mathrm{~h}$ in the presence or absence of cytochalasin D. All 
Fig. 5 Age causes strongest differences in gene expression and cell function. $\mathbf{a}$, b Bulk mRNA sequencing performed as in Fig. 4A-C. a Pairwise comparison of $\mathrm{TOM}^{+} \mathrm{cDC} 2$ from 8-day-old and adult mice indicating genes with a $\log _{2} \mathrm{FC}>1$ and padj $<0.05$ in red. $\mathbf{b}$ NES of gene sets enriched in TOM ${ }^{+}$ cDC2 from 8-day-old (red) or in CDC2 from adult mice (blue). c TOM + cDC2 from 2-week-old and adult Clec $9 a^{\text {cre }} /+$ RosaTOM mice were analyzed for expression of PD-L1 ( $n=5$, 2-week-old; $n=4$, adult) and CD38 ( $n=7$, 2-week-old; $n=6$, adult) (MFI = mean fluorescence intensity). d Splenic cDC2 from adult wild-type and Ifnar ${ }^{-/-}$mice were profiled for expression of PD-L1 and CD38 $(n=5)$. Expression levels are depicted as MFI. Each dot represents one mouse, horizontal bars represent mean, error bars represent SD. e-g TOM- DC2 and TOM ${ }^{+} \mathrm{cDC} 2$ from 2-week-old and TOM+ ${ }^{-} \mathrm{DC} 2$ from adult Clec9acre/+RosaTOM mice were sorted, pulsed with OVA ${ }_{323-339}$, and co-cultured with CTV-labeled OT-II cells under ThO or polarizing conditions for 3.5 days. e Left: CTV dilution of OT-II cells co-cultured with the indicated populations or CD11c-enriched splenocytes without OVA $323-339$ (gray). Right: division and proliferation indexes of OT-II cells after co-culture with the indicated DC2 populations $\left(n=5 / 6,2-\right.$ week-old TOM $^{+}$and TOM ${ }^{-} \mathrm{cDC}^{-}, n=4$, adult TOM $+c D C 2$ ). $\mathbf{f}$ T cells were analyzed for expression of Foxp3 and IL-17A. For Th17 conditions (right) numbers in each quadrant represent the mean \pm SD $(n \geq 7)$. $\mathbf{g}$ The percentage of cytokine or Foxp3-positive cells within proliferated OT-Il cells is shown. APC: T-cell ratio $1: 2$ for Th0, Th1, Th17 and $1: 10$ for Treg $\left(n=6\right.$, Th0/Th1; $n=3$, Treg; $n=8$, Th17; for 2-week-old TOM+ ${ }^{+}$DC2; $n=5$, Th0; $n=4$, Treg/Th1; $n=8$, Th17 for TOM ${ }^{-}$DC2; $n=4$, Th0/Th1/ Treg; $n=7$, Th17 for adult TOM $\left.{ }^{+} \mathrm{cDC}_{2}\right)$. h TOM ${ }^{+} \mathrm{cDC} 2$ from 2-week-old $(n=5)$ and adult mice $\left(n=6\right.$, Treg; $n=7$, Th17) were sorted as ESAM ${ }^{\text {high }}$ and ESAM $^{\text {low }}$ cells, pulsed with OVA $323-339$ and cultured with CTV-labeled OT-II cells under Treg and Th17 polarizing conditions as above. The percentage of cytokine or Foxp3-positive cells within proliferated OT-Il cells is shown. i TOM- DC2 and TOM ${ }^{+}$cDC2 from 2-week-old and TOM ${ }^{+} \mathrm{cDC}^{-}$from adult Clec9acre/+RosaTOM mice were co-cultured with OT-II cells in the presence of OVA under Th17 conditions for 4 days. The division index (left) and percentage of IL-17A producing OT-II cells (right, APC: T-cell ratio 1:2) are shown $(n=4)$. Each dot represents one biological replicate from four independent experiments, horizontal bars represent mean, error bars represent SD. ${ }^{\star \star \star} p<0.001,{ }^{\star \star \star \star} p<0.0001$. Statistical analysis was performed using two-tailed paired $t$-test (comparing TOM-DC2 and TOM ${ }^{+} \mathrm{CDC}^{-}$groups), one-way ANOVA (comparing 2-week-old and adult groups) or two-tailed $t$-test in $(\mathbf{c}, \mathbf{d}, \mathbf{h})$. Only statistically significant comparisons are indicated. Source data are provided as a Source Data file.

populations took up fluorescently labeled beads with similar efficiency (Supplementary Fig. 6H). Bead uptake was mediated by phagocytosis, as it was inhibited by cytochalasin D (Supplementary Fig. $6 \mathrm{H}$ ). Thus, $\mathrm{TOM}^{+} \mathrm{cDC}^{\mathrm{C}}$ and $\mathrm{TOM}^{-} \mathrm{DC} 2$ do not differ in their phagocytic ability. We next cultured $\mathrm{TOM}^{+} \mathrm{cDC}^{2}$ and $\mathrm{TOM}^{-}$DC2 from young mice and adult $\mathrm{TOM}^{+} \mathrm{cDC}^{-}$with CellTrace Violet (CTV)-labeled OT-II T cells in the presence of OVA under Th17 conditions (Fig. 5i). As observed before, $\mathrm{TOM}^{+} \mathrm{cDC} 2$ and $\mathrm{TOM}^{-}$DC2 from young mice induced a higher frequency of IL-17A-producing $\mathrm{T}$ cells than adult $\mathrm{cDC} 2$ (Fig. 5i). Thus, $\mathrm{TOM}^{+} \mathrm{cDC} 2$ and $\mathrm{TOM}^{-} \mathrm{DC} 2$ from young mice are comparable to their adult counterparts in their ability to process antigen and induce naive $\mathrm{T}$-cell proliferation in an antigen-specific manner. $\mathrm{TOM}^{+} \mathrm{CDC}_{2}$ and $\mathrm{TOM}^{-} \mathrm{DC} 2$ from young mice promoted similar Th17 and Treg differentiation; however, compared to adult cDC2, Th17 and Treg differentiation was increased, supporting the notion that distinct environmental cues in young and adult mice shape the ability of DCs to induce $\mathrm{T}$-cell differentiation. Although such cytokines could be regulated in response to the microbiota, $\mathrm{CDC} 2$ from adult mice housed in germ-free (GF) and specific pathogen-free (SPF) conditions induced similar OT-II cell differentiation under Th0, Th17, and Treg conditions, and did not recapitulate the phenotype of young CDC2 in terms of PDL-1 and CD38 expression (Supplementary Fig. 6I, J). These data suggest that functional differences of $\mathrm{cDC} 2$ in early life are not simply due to a lower microbial load at this age.

Early-life cDC2 induce distinct T-cell responses upon targeted antigen delivery compared to adult-life cDC2. Having established that $\mathrm{CDC} 2$ from young mice can activate $\mathrm{T}$ cells in vitro, we next asked whether $\mathrm{cDC} 2$ from young mice have this capacity upon direct delivery of antigens in vivo. We relied on an established method to target the model antigen OVA to $\mathrm{CDC} 2$ by coupling it to an antibody directed against the C-type lectin receptor CLEC4A4/DCIR2 25,107 . As $\mathrm{TOM}^{+} \mathrm{cDC}^{2}$ and $\mathrm{TOM}^{-}$ DC2 were phenotypically identical, we were unable to target either cell population individually but CLEC4A4 was expressed by both $\mathrm{TOM}^{+} \mathrm{cDC}$ and $\mathrm{TOM}^{-}$DC2 (Fig. 3a). We injected 2week-old Clec $9 a^{\text {cre/+}}{ }_{\text {Rosa }}{ }^{\text {TOM }}$ mice with anti-DCIR2-OVA or isotype-matched control antibody of irrelevant specificity. Twelve hours later, we sort-purified splenic $\mathrm{TOM}^{+} \mathrm{cDC}^{2}$ and $\mathrm{TOM}^{-}$
DC2, and co-cultured them with CTV-labeled OT-II T cells from adult mice (Fig. 6a) to overcome any T-cell intrinsic differentiation bias in early life ${ }^{2}$. In this experimental set up, $\mathrm{TOM}^{+} \mathrm{cDC} 2$ and $\mathrm{TOM}^{-}$DC2 induced OT-II proliferation upon targeting with anti-DCIR2-OVA but not isotype-matched control antibody (Fig. 6a). Thus, $\mathrm{TOM}^{+} \mathrm{cDC} 2$ and $\mathrm{TOM}^{-}$DC2 from 2 -week-old mice could be targeted with anti-DCIR2 and process antibody-antigen complexes for presentation to CD4 ${ }^{+} \mathrm{T}$ cells, although OT-II proliferation in the absence of adjuvant was low, as expected ${ }^{107}$.

Immune responses in early life are Th2 biased but such predisposition can be overcome through the use of Th1 adjuvants, such as CpG-B ${ }^{108,109}$. CpG-B signals through TLR9, which was similarly expressed between the profiled $\mathrm{CDC} 2$ populations in bulk mRNA sequencing (Supplementary Fig. 6A). Nonetheless, $\mathrm{TOM}^{+} \mathrm{cDC}^{2}$ and $\mathrm{TOM}^{-}$DC2 from 2-week-old and $\mathrm{TOM}^{+} \mathrm{cDC} 2$ from adult mice showed a distinct cytokine profile after CpG-B stimulation. In response to CpG-B TOM ${ }^{-}$DC2 from young mice were the most efficient cytokine producers and secreted higher amounts of IL-6, IL-12p40, and TNF- $\alpha$ than cDC2 from adults (Fig. 6b). Interestingly, IL-6 and TNF- $\alpha$ production were significantly higher in $\mathrm{TOM}^{-} \mathrm{DC} 2$ compared to $\mathrm{TOM}^{+} \mathrm{cDC} 2$ from young mice, raising the possibility that these cells have distinct inflammatory potential. Independent of origin cDC2 from young mice produced higher IL-10 and IL-27 than their adult counterparts (Fig. $6 \mathrm{~b}$ and Supplementary Fig. 7A). Although IL-27 production was low and not detectable in all samples, it is noteworthy, because DCs from peripheral blood of children show increased IL-27 production compared to DCs from adults $^{110}$. Thus, despite exhibiting similar Tlr9 expression cDC2 from young mice have different cytokine response to CpG-B than cDC2 from adults, indicating distinct signaling downstream of TLR9 and supporting the hypothesis that age imprints $\mathrm{CDC} 2$ with distinct immune reactivity.

We next tested whether the distinct response to CpG-B stimulation would influence the ability of $\mathrm{cDC} 2$ to activate $\mathrm{T}$ cells and induce their differentiation. We injected 2.5-week-old or adult mice with anti-DCIR2-OVA in the presence of CpG-B as adjuvant. Twelve hours later, we sorted $\mathrm{TOM}^{+} \mathrm{cDC}$ and $\mathrm{TOM}^{-}$ DC2 from young mice, as well as $\mathrm{TOM}^{+} \mathrm{cDC}_{2}$ from adult mice and co-cultured them with CTV-labeled OT-II T cells isolated from adult mice (Fig. 6c, d). After 3.5 days, T-cell proliferation, cytokine production, and Foxp3 expression were analyzed. In this 
a

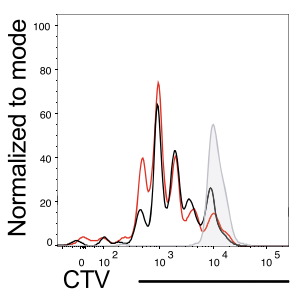

b
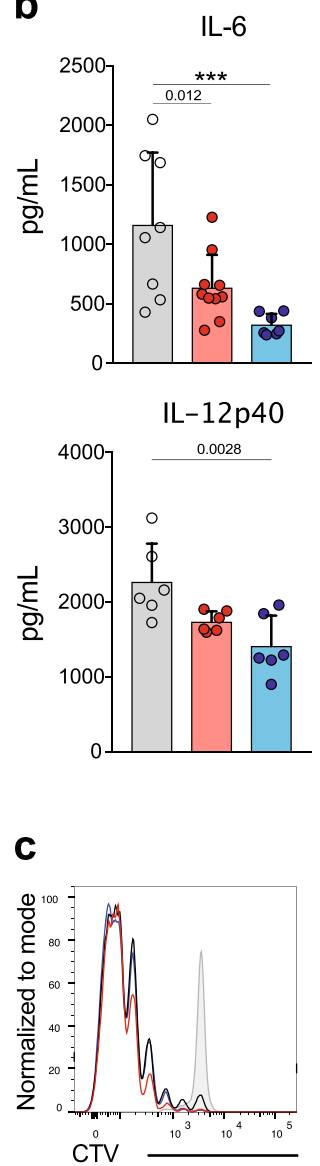

d

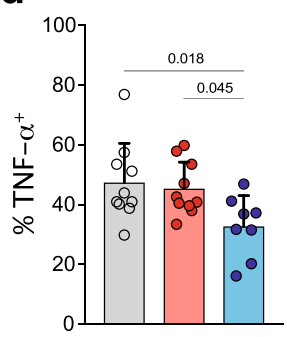

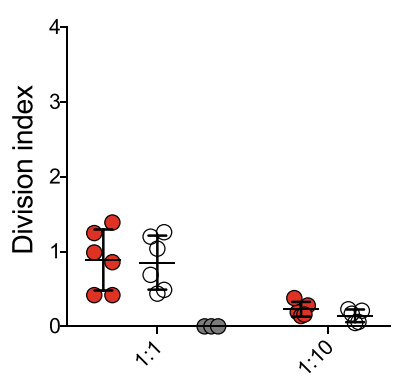

APC:T cell ratio
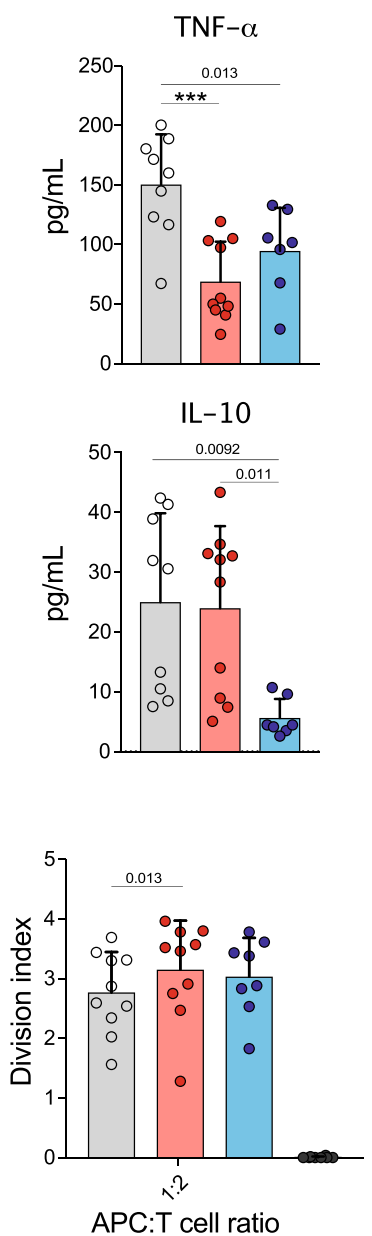

OTOM-DC2

$\mathrm{TOM}^{+} \mathrm{CDC2}$ young

$\mathrm{TOM}^{+} \mathrm{CDC} 2$ adult

cDC1 young

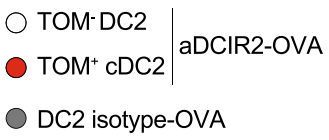

\begin{tabular}{l|l}
$\mathrm{TOM}^{-} \mathrm{DC} 2$ & young \\
$\mathrm{TOM}^{+} \mathrm{CDC2}$ & CpG-B
\end{tabular}

$\mathrm{TOM}^{+} \mathrm{CDC} 2$ adult
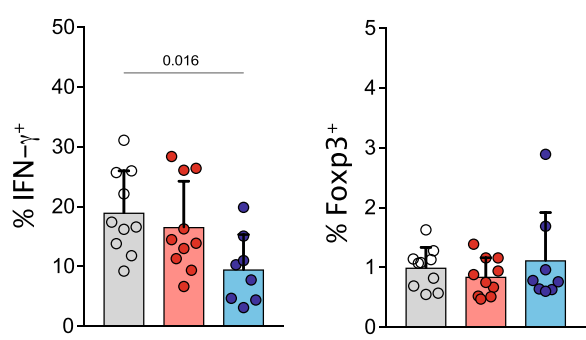

TOM-DC2

$\mathrm{TOM}^{+} \mathrm{CDC2}$ young

$\mathrm{TOM}^{+} \mathrm{cDC} 2$ adult

assay, $\mathrm{TOM}^{+} \mathrm{cDC} 2$ and $\mathrm{TOM}^{-} \mathrm{DC} 2$ from young mice and $\mathrm{CDC} 2$ from adult mice induced similar OT-II T-cell proliferation (Fig. 6c). Targeting was cell-type specific as cDC1 did not promote T-cell proliferation (Fig. 6c). Importantly, $\mathrm{T}$ cells stimulated with $\mathrm{TOM}^{+} \mathrm{CDC} 2$ and $\mathrm{TOM}^{-} \mathrm{DC} 2$ from young mice produced more TNF- $\alpha$ than T cells stimulated with CDC2 from adult mice (Fig. 6d). Notably, this is in contrast to splenic human $\mathrm{cDC} 2$ from fetal tissue, which suppress T-cell-derived TNF- $\alpha$ through ARGINASE $2^{43}$. T cells stimulated with TOM ${ }^{-}$ DC2 from young mice also produced more IFN- $\gamma$ than T cells stimulated with $\mathrm{CDC} 2$ from adult mice (Fig. $6 \mathrm{~d}$ and Supplementary Fig. 7B). Increased IFN- $\gamma$ production was also observed for T cells stimulated with $\mathrm{TOM}^{+} \mathrm{cDC} 2$ from young mice compared to $\mathrm{cDC} 2$ from adults (Fig. 6d and Supplementary Fig. 7B), 
Fig. 6 Early-life cDC2 induce distinct T-cell responses upon targeted antigen delivery compared to adult-life cDC2. a 2-Week-old Clec9acre/ $+R o s a T O M$ mice were injected i.p. with aDCIR2-OVA or isotype-OVA control antibody. After $12 \mathrm{~h}, \mathrm{TOM}^{+} \mathrm{cDC} 2$ and TOM ${ }^{-} \mathrm{DC}^{2}$ were sorted and co-cultured with OT-II cells for 3.5 days. CTV dilution (left) and division index of OT-Il cells after co-culture with the indicated DC2 populations (right) are shown ( $n=6,1: 1$ ratio; $n=5,1: 10$ ratio; $n=3$, isotype-OVA). $\mathbf{b ~ T O M}^{+} \mathrm{cDC}$ and TOM ${ }^{-} \mathrm{DC} 2$ from 2 -week-old and TOM ${ }^{+} \mathrm{cDC}$ from adult Clec9acre/ + RosaTOM mice were sorted and stimulated with CpG-B. Cytokine production was analyzed 18-20 h later. Each dot represents a biological replicate from 4 (IL-6, TNF- $\alpha$, and IL10) or two (IL-12p40) independent experiments. c, d 2-Week-old and adult Clec9acre/+RosaTOM mice were injected i.p with anti-DCIR2-OVA antibody plus CpG-B. After $12 \mathrm{~h}$ DC populations were sorted and co-cultured with OT-II T cells as in a. c CTV dilution (left) and division index (right) of OT-II cells after co-culture with the indicated DC populations ( $n=10,2$-week-old; $n=8$, adult and cDC1 from 2-week-old mice). d Percentage of TNF- $\alpha$, IFN- $\gamma$, and Foxp3positive cells within proliferated OT-II cells $(n=10,2$-week-old; $n=8$, adult). Each dot represents one biological replicate from at least three independent experiments, horizontal bars represent mean, error bars represent SD. ${ }^{\star \star \star} p<0.001$. Statistical analysis was performed using two-tailed paired $t$-test (comparing TOM ${ }^{-} \mathrm{DC} 2$ and $\mathrm{TOM}^{+} \mathrm{cDC} 2$ groups) or one-way ANOVA (comparing 2-week-old and adult groups). Only statistically significant comparisons are indicated. Source data are provided as a Source Data file.

although differences did not reach statistical significance. Thus, $\mathrm{TOM}^{+} \mathrm{cDC}_{2}$ and $\mathrm{TOM}^{-} \mathrm{DC} 2$ from young mice induced more TNF- $\alpha$ production from $\mathrm{T}$ cells and greater Th1 differentiation than adult $\mathrm{cDC} 2$. Increased Th1 differentiation could be related to the slight increase in IL-12p40 production in $\mathrm{CDC} 2$ from young compared to adult mice upon CpG-B stimulation (Fig. 6b); however, it is likely that other factors, such as costimulatory molecules (Fig. 5a), also contribute. Notably, production of Th2 cytokines and Foxp3 expression was similar between $\mathrm{T}$ cells stimulated with cDC2 from young and adult mice (Fig. 6d and Supplementary Fig. 7B) and Th17 cytokine production was not observed. Taken together, early-life $\mathrm{TOM}^{+}{ } \mathrm{cDC}_{2}$ and $\mathrm{TOM}^{-}$ DC2 are fully capable of inducing $\mathrm{T}$-cell proliferation upon targeted antigen delivery in vivo but in the context of CpG-B stimulation early-life $\mathrm{cDC} 2$ induce an increased Th1 response compared to adult-life cDC2.

\section{Discussion}

The cDC compartment in early, compared to adult life, exhibits quantitative and qualitative differences in its ability to induce immunity, leading some to suggest that $\mathrm{cDC}$ in early life may be functionally immature. Here we set out to define the reasons underlying age-dependent functional differences of cDCs. We demonstrate that early-life $\mathrm{cDC} 2$ exhibit a distinct hematopoietic origin and, similar to other myeloid and lymphoid cells, develop sequentially at specified times during development. In contrast to other cell types that develop in waves ${ }^{42,80-82}$, cell origin appeared negligible for cell function, as ontogenetically distinct cDC2 in early life were transcriptionally and functionally similar and within 2 weeks after birth could prime naive $\mathrm{T}$ cells at levels comparable to $\mathrm{cDC} 2$ from adult mice. Instead our data suggest that cytokine environments in early and adult life imprint $\mathrm{CDC} 2$ with a distinct gene expression profile that alters their ability to respond to pathogenic stimuli, secrete cytokines, and induce $\mathrm{T}$ cell differentiation. Thus, $\mathrm{cDC} 2$ in early life are functionally capable but transcriptionally pre-disposed to respond differently to pathogens and induce distinct $\mathrm{T}$-cell responses than their adult counterparts.

In early life, the majority of $\mathrm{cDC} 2$ originated from $\mathrm{Clec} 9 a$ negative progenitors denoted here as $\mathrm{TOM}^{-} \mathrm{DC} 2$. These cells were replaced within the first few weeks after birth by cells arising from bona fide Clec $9 a$-expressing myeloid cDC progenitors, denoted as $\mathrm{TOM}^{+} \mathrm{cDC} 2$. Coinciding with the increase in Clec9a-cre expression history, we found evidence of a lymphoid contribution to the early-life cDC2 compartment using Rag1 ${ }^{\text {cre }}$ and $I l 7 r^{\text {cre }}$ mice that declined with age. Rag $1^{\text {cre }}$ also labels the progeny of yolk sac-derived lymphomyeloid primed progenitors ${ }^{66}$ and $I l 7 r^{c r e}$ expression history is found in macrophages of yolk sac origin ${ }^{111}$. As we exclude a yolk sac origin but demonstrate $\mathrm{cDCs}$ to be $M y b$-dependent, our data indicate an HSC- derived lymphoid contribution to early-life cDCs. Such lymphoid progenitors likely arise from fetal liver-resident progenitors, as we find splenic cDC2 as early as E16.5 (Fig. 2c and Supplementary Fig. 1D), at which stage hematopoiesis has yet to colonize bone marrow ${ }^{112,113}$. This notion is further supported by in utero CXcr $4^{\text {creER }}$ fate mapping 77 . A lymphoid path to generating $\mathrm{cDCs}$ has been suggested ${ }^{69,71-74}$ but does not contribute to the steadystate $\mathrm{cDC}$ pool in adult mice $48,74,76$. Our data suggest that lymphopoiesis contributes to the CDC compartment of mice in early life. Such layered ontogeny is reminiscent of other immune cells that develop in waves during development, including macrophages, mast cells, ILCs, B, and T cells ${ }^{42,80,81,114,115}$. Although layered immune development can generate progressively adapted immune populations ${ }^{80-82}, \mathrm{TOM}^{+} \mathrm{cDC}^{\mathrm{CD}}$ and $\mathrm{TOM}^{-} \mathrm{DC} 2$ exhibit apparently identical phenotype, transcriptional profile, and similar cell function, which is consistent with other studies comparing human and murine cDCs generated from lymphoid or myeloid progenitors ${ }^{74,116}$. It is possible that functional differences exist between $\mathrm{TOM}^{+}{ }^{\mathrm{cDC}} 2$ and $\mathrm{TOM}^{-} \mathrm{DC} 2$ in situations that we have not yet explored; however, lymphopoiesis may compensate DC poiesis when bona fide $\mathrm{CDC}$ progenitors are not present in sufficient quantities to generate a full repertoire of $\mathrm{cDCs}^{74}$. This hypothesis is consistent with the low frequency of CDPs and precDCs in bone marrow from neonatal compared to adult mice. Whether cDC-like cells in early life arise from lymphoidcommitted progenitors, such as CLPs, or from conversion of already differentiated lymphoid cells, such as pDCs or ILCs ${ }^{117-}$ 119 needs to be investigated. We and others have proposed that cDCs and other mononuclear phagocytes should predominantly be defined on the basis of their ontogen $y^{5,114,120}$; however, our data imply that an ontogenetic view to cell definition may not be plausible if populations with different origins turn out to be identical by all measures examined ${ }^{74,79,121-123}$.

In continuation of earlier studies $9,10,17$, we profiled the cDC compartment by flow cytometry with age using large marker panels. We demonstrate that the major subsets of splenic $\mathrm{cDCs}$, including $\mathrm{CDC} 1$, non-canonical $\mathrm{CD}^{+} \mathrm{cDCs}$, as well as ESAM ${ }^{\text {high }}$ and ESAM ${ }^{\text {low }} \mathrm{CDC} 2$, are present in murine spleen as early as 1 week after birth. These findings were further substantiated using unbiased dissection of the cDC compartment of 1-week-old mice using scRNA-seq. In this analysis, $\mathrm{cDC1}$ segregated across several clusters, possibly reflecting functional heterogeneity within this compartment ${ }^{17,124}$. Non-canonical $\mathrm{CD}^{+} \mathrm{cDCs}$ were positioned more closely to $\mathrm{cDC} 2$ than $\mathrm{pDCs}$ or $\mathrm{cDC} 1$, which is consistent with bulk transcriptome profiling in adult mice ${ }^{59,60}$. Although non-canonical $\mathrm{CD}^{+}{ }^{+} \mathrm{cDCs}$ were recently suggested to constitute a transitional cell type with $\mathrm{pDC}$ and $\mathrm{cDC} 2$ characteristics in adult mice ${ }^{125}$, our data indicate non-canonical $\mathrm{CD} 8^{+} \mathrm{cDCs}$ as a unique DC subset with close resemblance to $\mathrm{CDC} 2$ in early life. In scRNA-seq, early-life cDC2 spread across two main clusters resembling $\mathrm{ESAM}^{\text {high }}$ and $\mathrm{ESAM}^{\text {low }}$ subsets found in adult 
spleen $^{62}$, which, despite being profiled at a different age, also resembled the T-bet-positive and T-bet-negative $\mathrm{cDC} 2$, respectively ${ }^{92}$. We also identified a cluster of cells resembling migratory cDCs, which has recently been observed in adult spleen ${ }^{92}$. Importantly, scRNA-seq revealed $\mathrm{TOM}^{-} \mathrm{DC} 2$ and $\mathrm{TOM}^{+} \mathrm{cDC} 2$ as transcriptionally identical. Although bulk RNA-seq identified differences in gene expression between $\mathrm{TOM}^{-} \mathrm{DC} 2$ from $\mathrm{TOM}^{+}$ cDC2, we could correlate these genes to a unique cluster of Rorcexpressing cells that transcriptionally resembles $\mathrm{cDC} 2$ but lacks Clec $9 a^{\text {cre }}$ expression history. Accordingly, ROR $\mathrm{yt}^{+}$cells could be identified by flow cytometry within $\mathrm{TOM}^{-}$DC2 in early life but $\mathrm{ROR} \gamma \mathrm{t}^{+} \mathrm{cDC} 2$ were not found in adult spleen. Rorc $^{\mathrm{Cre}}$-mediated fate mapping and trajectory analyses indicate that these cells are unlikely to serve as progenitors for $\mathrm{CDC} 2$ or other $\mathrm{CDC}$ subsets. The fact that Rorc-expressing cluster 11 segregated away from the putative ROR $\gamma$ t-regulated $\mathrm{CDC} 2 \mathrm{~B}^{92}$ (cluster 3 ) further supports that $\mathrm{ROR}_{\mathrm{t}} \mathrm{t}^{+} \mathrm{TOM}^{-} \mathrm{DC} 2$ constitute a unique $\mathrm{CDC}$ subtype present transiently during early life.

Although in adult spleen ESAM ${ }^{\text {high }}$ cells constituted the dominant $\mathrm{CDC} 2$ population, this subset was a minority of $\mathrm{CDC} 2$ in mice under 1 week of age. ESAM ${ }^{\text {high }}$ and ESAM ${ }^{\text {low }} \mathrm{CDC} 2$ can activate $\mathrm{CD}^{+} \mathrm{T}$ cells but they may differ in their ability to promote effector differentiation ${ }^{62,92,126}$. We mostly characterized bulk cDC2 in 2- to 2.5-week-old mice when ESAM ${ }^{\text {high }}$ and ESAM $^{\text {low }}$ subset distribution had reached adult levels, because sufficient $\mathrm{TOM}^{+} \mathrm{cDC}^{2}$ and $\mathrm{TOM}^{-} \mathrm{DC} 2$ could be isolated to probe cell function. At this time, splenic $\mathrm{TOM}^{+} \mathrm{CDC}_{2}$ and $\mathrm{TOM}^{-}$DC2 were fully capable of initiating T-cell activation but they induced greater Th17 and Treg differentiation under in vitro polarizing conditions than adult $\mathrm{cDC} 2$. These observations could be correlated to the unique gene expression profile of $\mathrm{CDC} 2$ in early and adult life. Early-life cDC2 expressed higher levels of factors known to promote Tregs, such as Lgals1, Aldh2, and Sema $4 a^{100-103,106}$, suggesting increased tolerogenic potential of cDC2 in early life, which is also consistent with their greater IL-10 production in response to $\mathrm{CpG}-\mathrm{B}$ stimulation. Higher levels of Il6ra on $\mathrm{cDC} 2$ from young mice could increase IL-6 transpresentation ${ }^{104}$ and promote Th17 differentiation in conjunction with reduced expression of Tnfsf4 (OX40L) and Cd274 (PD-L1) in early life, which can suppress Th17 differentiation $97,98,127,128$. Some of these age-dependent transcriptional changes could be related to small differences in the composition of $\mathrm{CDC} 2$ in 1week-old and adult mice. We nonetheless consider age to be the most prominent contributor to variation, because we demonstrated that both ESAM ${ }^{\text {high }}$ and ESAM ${ }^{\text {low }}$ CDC2 function differently in early and adult life.

The notion that $\mathrm{cDC} 2$ are equipped with an age-dependent gene expression profile that alters their ability to induce T-cell differentiation was further supported using targeted antigen delivery to cDC2 in early and adult life followed by ex vivo antigen presentation ${ }^{25,107}$. This approach allowed us to (a) compare cell function in vivo across age, while excluding agedependent functional regulation of other immune components as confounding factor and (b) to demonstrate the potential to target cDC2 to induce T-cell responses. CpG-B was chosen as adjuvant, because despite similar Tlr9 expression across age, $\mathrm{TOM}^{+}{ }^{\mathrm{cDC} 2}$, and $\mathrm{TOM}^{-}$DC2 from 2 -week-old mice showed distinct cytokine production after CpG-B stimulation in vitro, including higher levels of IL-12p40, IL-6, IL-10, and IL-27, supporting a distinct immune reactivity of $\mathrm{CDC} 2$ with age. IL-27 is a pleiotropic cytokine with pro- and anti-inflammatory properties in multiple cell types ${ }^{129}$, but after vaccination in mice its expression correlates with protective $\mathrm{CD}^{+} \mathrm{T}$-cell responses ${ }^{130}$. DCs from peripheral blood of children show higher IL-27 production than DCs from adults ${ }^{110}$ but whether cDC2-derived IL-27 plays a role in early-life immunity needs to be investigated. Despite producing increased amounts of IL-10, which dampens $\mathrm{CD}^{+}{ }^{+} \mathrm{T}$-cell responses ${ }^{131}$, early-life $\mathrm{TOM}^{+} \mathrm{cDC}$ and $\mathrm{TOM}^{-} \mathrm{DC} 2$ induced similar OT-II T-cell proliferation compared to cDC2 from adults upon DCIR2-mediated antigen targeting in the context of CpG stimulation. However, early-life cDC2 induced greater Th1 differentiation and TNF- $\alpha$ production from $\mathrm{T}$ cells. Human fetal DC2 suppress TNF- $\alpha$ production from $\mathrm{T}$ cells ${ }^{43}$, suggesting that cDC2 function changes dynamically after birth. Transcriptional profiling of fetal and neonatal $\mathrm{cDC} 2$, possibly at the single-cell level, may provide further insights into the processes involved in shaping early-life cDC2 function. Differences in cytokine production and T-cell stimulatory capacity between $\mathrm{cDC} 2$ from young and adult mice were not simply regulated at the level of PRR expression but most probably involve downstream signaling events, costimulatory molecules, or epigenetic modification. Therefore, it is likely that age-dependent differences in cDC2 function will be magnified when cells are stimulated through PRRs with differential gene expression across age and additional adjuvants must be tested for their ability to promote cDC2mediated T-cell priming and differentiation with age.

Our studies indicate that splenic cDC2 do not exhibit a Th2 bias, which is in contrast to $\mathrm{CDC} 2$ in the developing lung. In this organ, IL-33 induces OX40L expression on cDC2, which promotes Th2 skewing ${ }^{30}$. Therefore, site-specific cytokine environments appear to play a major role in imprinting $\mathrm{cDC}$ function in different organs and with age. This is consistent with previous studies $^{38,92}$ and our observation that $\mathrm{cDC} 2$ from adult compared to young mice showed an enrichment of genes involved in signaling downstream of IL-2, IFN- $\gamma$, TNF- $\alpha$, and IFN- $\alpha$. In our hands, cDC2 from GF mice did not recapitulate the phenotypic and functional features of neonatal cDC2. Although GF mice have a complete absence of commensals, in an SPF environment CDC2 are expected to encounter a variety of microbial signals within the first days of birth. We therefore believe that these observations do not exclude the possibility that microbially derived signals or signals induced in response to commensals play a role in imprinting $\mathrm{CDC} 2$ function with age. During weaning, the intestinal microbiota induces a cytokine response termed the "weaning reaction," which is required for normal immune development ${ }^{132}$. As cDC2 function in our hands has been assessed before this period, it is intriguing to speculate that cytokines or other factors that change in response to alterations in commensals or diet during weaning are involved in shaping $\mathrm{cDC}$ function with age. Such effects could even be mediated by lasting alterations on progenitor populations similar to the concept of trained immunity.

Neonates are highly susceptible to infections with Candida albicans, Bordetella pertussis, and Streptococcus pneumoniae, which can cause life-threatening complications in early life $\mathrm{l}^{1,133,134}$. Defense against these pathogens requires Th17 responses ${ }^{135,136}$. Our demonstration that early-life cDC2 are fully capable of activating naive $\mathrm{CD} 4^{+} \mathrm{T}$ cells, and supporting Th1 and Th17 differentiation highlights the potential of harnessing these cells for boosting protective immunity in early life. This could for instance be achieved by delivering antigens specifically to $\mathrm{CDC} 2$ in the context of adjuvants that target age-specific parameters of cDC2 function.

\section{Methods}

Mice. Clec9a ${ }^{\text {tm2.1(icre)Crs }}$ (Clec9a-cre) 48 (Jackson Laboratory Stock No: 025523), Gt (ROSA)26Sor ${ }^{\text {tml(EYFP)Cos }}$ (Rosa26 lox-STOP-lox-EYFP) ${ }^{137}$ (Jackson Laboratory Stock No: 006148), Gt(ROSA)26Sor ${ }^{\text {tm9(CAG-tdTomato)Hze }}$ (Rosa26 lox-STOP-lox-tdtomato) ${ }^{91}$ (Jackson Laboratory Stock No: 007909), Tg(Csf1r-cre/Esr1*)1Jwp (Csf1r Mer-iCre-Mer $)^{138}$ (Jackson Laboratory Stock No: 019098), Flt3l ${ }^{\mathrm{tml} I m x}\left(\text { Flt3l }^{-l-}\right)^{65}$ (MMRRC Stock No: 37395-JAX), Myb ${ }^{\text {tmlSsp }}\left(M y b^{+/-}\right)^{68}$ (Jackson Laboratory Stock No: 004757), Rag1 ${ }^{\text {tml(cre)Thr }}$ (Rag1 $\left.^{\text {cre }}\right)^{139}, \operatorname{Tg}\left(\right.$ TcraTcrb) 425 Cbn $(\mathrm{OT}-\mathrm{II})^{140}$ (Jackson Laboratory Stock No: 004194) crossed to a Thy1.1 (CD90.1) background, Tg(Rorc-EGFP)1Ebe 
(RorceGFP) ${ }^{141}$, Cxcr4 $^{\text {creER77 }}$, Gt(ROSA)26Sor ${ }^{\text {tm4(ACTB-tdTomato,-EGFP)Luo/ }}$ J (Rosa $\left.{ }^{m T m G}\right)^{142}$ (Jackson Laboratory Stock No: 007576), Ly5.1 (CD45.1) B6.SJL (Jackson Laboratory Stock No: 002014), and C57BL/6J mice were bred at the Biomedical Center or Walter-Brendel-Centre for Experimental Medicine. $\mathrm{Tg}$ (Rorc-cre)

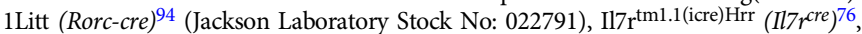
and Gt(ROSA)26Sor ${ }^{\text {tmlHjif }}$ (Rosa26 lox-STOP-lox-RFP)143 (EMMA strain ID EM:02112) mice were bred at the University of Birmingham, UK. Ifnar $1^{\text {tml Agt }}\left(\text { Ifnar }^{-1-}\right)^{144}$ (MMRRC Stock No: 32045-JAX) mice were bred at the University Hospital Erlangen, Germany. Mice were maintained in SPF conditions with a $12 \mathrm{~h}$ dark/light cycle, in individually vented cages (type II long, measuring $18 \times 30 \times 13 \mathrm{~cm}$ with stocking density according to EU guideline 2010/63) supplied with autoclaved bedding, play tunnels, nestles, and mouse houses. Irradiated food and sterile filtered and ultravioletlight exposed water were provided ad libitum. Cage manipulations took place in laminar flow hoods. Air temperature was $22 \pm 2{ }^{\circ} \mathrm{C}$ and humidity $55 \pm 10 \%$ with daily control and record. GF mice were provided by Dirk Haller. For timed matings, mice of desired genotypes were mated overnight. Embryonic development was estimated considering the day of vaginal plug formation as E0.5. Mice over the age of 8 weeks were considered adults. The neonatal period was defined as the first 10 days of life. Mice younger than 3 weeks of age were killed by decapitation. Adult mice were killed by cervical dislocation. Mice were sex-matched but male and female mice were used for all experiments. In most experiments, littermates were used. When littermates could not be used, e.g., in experiments involving mice of different age, mice were kept under the same barrier conditions and in the same racks. All animal procedures were performed in accordance with national and institutional guidelines for animal welfare and approved by the Regierung of Oberbayern.

Cell isolation for flow cytometry. Spleens were minced into small pieces and digested in $1 \mathrm{~mL}$ of RPMI (Thermo Fisher Scientific) with $200 \mathrm{U} / \mathrm{mL}$ collagenase IV (Worthington) and $0.2 \mathrm{mg} / \mathrm{mL}$ DNAse I (Roche) for $30 \mathrm{~min}$ at $37^{\circ} \mathrm{C}$ while shaking. After digestion, cells were passed through a $70 \mu \mathrm{m}$ strainer and washed once with FACS buffer (phosphate-buffered saline (PBS), 1\% fetal calf serum (FCS), $2.5 \mathrm{mM}$ EDTA, $0.02 \%$ sodium azide). Erythrocytes were lysed with Red Blood Cell Lysing Buffer Hybri-Max (Sigma-Aldrich) for $2 \mathrm{~min}$ at room temperature (RT), washed once, and resuspended in FACS buffer for further analysis. Bone marrow from adult mice was isolated from femurs and tibiae by flushing, and bone marrow from mice under 2 weeks of age was isolated by crushing the bones through a $70 \mu \mathrm{m}$ cell strainer. Erythrocytes were lysed as above and cells were resuspended in FACS buffer for further analysis. Liver was minced into small pieces and digested in $2 \mathrm{~mL}$ PBS containing $\mathrm{Mg}^{2+}$ and $\mathrm{Ca}^{2+}$ (Sigma-Aldrich) with $1 \mathrm{mg} / \mathrm{mL}$ collagenase IV (Worthington), $60 \mathrm{U} / \mathrm{mL}$ DNAse I (Roche), $2.4 \mathrm{mg} / \mathrm{mL}$ Dispase II (Roche), and 3\% FCS (Sigma-Aldrich) for $30 \mathrm{~min}$ at $37^{\circ} \mathrm{C}$ while shaking. After digestion, cells were passed through a $100 \mu \mathrm{m}$ strainer and centrifuged for $3 \mathrm{~min}$ at $50 \mathrm{~g}$ at $4{ }^{\circ} \mathrm{C}$, to pellet hepatocytes. The supernatant was collected and recentrifuged for $7 \mathrm{~min}$ at $320 \times g$ at $4{ }^{\circ} \mathrm{C}$. Pelleted cells were resuspended in FACS buffer for further analysis.

\section{Cell isolation for cell sorting and functional analyses. Cell isolation from spleen} was performed as above but FACS buffer without sodium azide was used for all functional and RNA profiling experiments. For sorting of $\mathrm{cDC} 2 \mathrm{CD} 11 \mathrm{c}^{+}$cells were enriched from splenic single-cell suspensions by positive selection using antiCD11c magnetic beads and LS columns (Miltenyi) according to the manufacturer's instructions. For OT-II cell isolation, the spleen was mechanically disrupted through a $70 \mu \mathrm{m}$ strainer and washed once with FACS buffer without sodium azide. OT-II cells were then enriched from total splenocytes using the EasySep ${ }^{\mathrm{wn}}$ Mouse Naive $\mathrm{CD}^{+} \mathrm{T}$ Cell Isolation Kit (Stemcell Technologies) according to the manufacturer's instructions. Erythrocytes were not lysed prior to OT-II cell enrichment, following the manufacturer's recommendations.

Flow cytometry. For staining of surface epitopes, cells were incubated first in $50 \mu \mathrm{L}$ with purified anti-mouse CD16/32 (FcBlock) for $10 \mathrm{~min}$ at $4{ }^{\circ} \mathrm{C}$, before additional antibodies were added to a final staining volume of $100 \mu \mathrm{L}$ in a $2 \times$ Mastermix. Cells were stained at $4{ }^{\circ} \mathrm{C}$ for $20 \mathrm{~min}$ then washed twice and resuspended in FACS buffer for analysis. CCR6 staining was performed at $37^{\circ} \mathrm{C}$ for $45 \mathrm{~min}$ before staining with additional antibodies. For intracellular staining, cells were first stained with antibodies against surface epitopes in the presence of fixable viability dye eFluor ${ }^{\text {sin }} 780$ (Thermo Fisher Scientific) and then washed with FACS buffer. Intracellular staining for cytokines was performed using intracellular Fixation \& Permeabilization Buffer Set and intranuclear staining was performed with the Foxp3 transcription factor staining set (both Thermo Fisher Scientific) according to the manufacturer's instructions. A pre-fixation step with $2 \%$ paraformaldehyde at RT for $15 \mathrm{~min}$ was performed after surface epitope staining to preserve TOMATO signal during intranuclear staining. Dead cells were excluded from analysis by $4^{\prime}, 6-$ diamidino-2-phenylindole staining (Sigma-Aldrich) for live samples or fixable viability dye eFluor 780 (Thermo Fisher Scientific). Data were collected on an LSR Fortessa (BD Biosciences) using BD FACSDiva Software (BD BioSciences, Version 8) and data analysis was performed using FlowJo software (Tree Star, Inc.). Cell sorting was performed on an Aria III Fusion (BD Biosciences). Cells counts were quantified using CountBright ${ }^{\text {mit }}$ Absolute Counting Beads (Thermo Fisher Scientific). Mean fluorescence intensity was calculated as the geometric mean of the indicated fluorescent parameter using FlowJo software (Tree Star, Inc.). Antibodies used for flow cytometry are provided in Supplementary Data 4.

Immunofluorescence microscopy. Spleens were fixed overnight at $4{ }^{\circ} \mathrm{C}$ in paraformaldehyde, then dehydrated in P-buffer $\left(0.2 \mathrm{M} \mathrm{Na}_{2} \mathrm{HPO}_{4}\right.$ and $0.2 \mathrm{M} \mathrm{NaH}_{2} \mathrm{PO}_{4}$ at an $81: 19$ analogy), containing $30 \%$ sucrose overnight at $4^{\circ} \mathrm{C}$ as described ${ }^{145}$, transferred to Tissue-Tek O.C.T. (Sakura), and frozen on dry ice. Twelvemicrometer-thick frozen sections were cut on a cryostat at $-20{ }^{\circ} \mathrm{C}$ (Leica CM3050S), rehydrated in PBS, and permeabilized with Acetone (Sigma-Aldrich). Afterwards, the sections were circled with a PAP Pen (Kisker Biotech GmbH) and blocked for $1 \mathrm{~h}$ at RT in the dark with blocking buffer containing $10 \%$ goat serum in PBS. Antibodies were diluted in blocking buffer and sections were incubated for $2 \mathrm{~h}$ at RT in the dark with the antibody mixture. Finally, stained sections were washed with PBS, mounted with ProLong ${ }^{\text {mi }}$ Diamond Antifade Mountant (Thermo Fisher Scientific), cured at RT for $24 \mathrm{~h}$ in the dark, and stored at $4{ }^{\circ} \mathrm{C}$ until imaging. Confocal microscopy was performed at the Core Facility Bioimaging of the Biomedical Center with an upright Leica SP8X WLL microscope, equipped with $405 \mathrm{~nm}$ laser, WLL2 laser (470 - $670 \mathrm{~nm}$ ), and acusto-optical beam splitter. Threedimensional tile scans were acquired with a $20 \times 0.75$ objective, image voxel size was $180 \mathrm{~nm}$ in $x / y$ direction and 0.5 in $z$ direction. The following channel settings were used: BV421 (excitation $405 \mathrm{~nm}$; emission 415-470 nm), AF488 (500; 510-542), TOMATO (553; 563-591), AF594 (592; 605-640), and AF647 (650; 656-718). Recording was done sequentially to avoid bleed-through. BV421, AF488, AF594, AF647, and TOMATO were recorded with hybrid photo detectors. Tile scans were merged in LAS X (Leica, Version 3.4.1.17670). Images were imported in Fiji 146 to create maximum projections, adjust brightness/contrast, and to add scale bars. Antibodies used for microscopy are provided in Supplementary Data 4.

Pulse labeling of yolk sac progenitors. For labeling of yolk sac-derived macrophages, heterozygous Csfir Mer-iCre-Mer mice were crossed with homozygous Rosa ${ }^{Y F P}$ reporter mice. Pregnant females were injected at E8.5 with a single dose of $75 \mu \mathrm{g}$ per gram body weight 4 -hydroxytamoxifen ( $4^{\prime} \mathrm{OHT}$, Sigma-Aldrich) supplemented with $37.5 \mu \mathrm{g}$ per gram body weight progesterone (Sigma-Aldrich) ${ }^{41}$. The spleen and liver of F1 mice were analyzed at embryonic day 18.5, as well as at 2 and 4 weeks after birth by flow cytometry.

RNA isolation, library construction, and RNA-seq analysis. $C D 11 c^{+}$cells were enriched from splenocytes of adult and 1-week-old Clec $9 a^{\text {cre/cre }}$ Rosa $^{T O M}$ mice. $\mathrm{CDC} 2$ were identified as live, single, autofluorescence-negative, $\mathrm{CD} 11 \mathrm{c}^{+} \mathrm{MHCII}{ }^{+} \mathrm{CD} 11 \mathrm{~b}^{+}$ cells, and divided based on TOMATO expression into $\mathrm{TOM}^{+} \mathrm{cDC}^{+}$and $\mathrm{TOM}^{-}$ DC2. Spleens from 1-week-old mice were pooled to increase the yield of sorted cells. Total RNA was isolated using column-based PicoPure ${ }^{\mathrm{mu}}$ RNA Isolation Kit (Thermo Fisher Scientific). RNA quality was assessed using a 2100 Bioanalyzer (Agilent) and samples with RNA Integrity Number $>8$ were used for cDNA synthesis by using ultra-low input RNA SMART-seq v4 kit (Clontech) according to the manufacturer's instructions. cDNA was transferred to AFA Fiber Pre-Slit Snap-Cap $6 \times 16 \mathrm{~mm}$ microTUBEs (Covaris) and sheared by sonication. Sheared cDNA was cleaned using ethanol precipitation and sonication efficiency was determined using the 2100 Bioanalyzer. A maximum of $10 \mathrm{ng}$ sheared cDNA was used to generate libraries for RNA-seq with the MicroPlex Library Preparation kit v2 (Diagenode). The libraries were amplified until a DNA concentration above $5 \mathrm{ng} / \mu \mathrm{L}$ was reached as determined by Qubit 2 DNA quantification (Thermo Fisher Scientific). Amplified libraries were cleaned using AMPure XP beads (Beckman Coulter) as described in the SMART-seq $\mathrm{v} 4$ kit (Clontech) protocol and the final concentration, as well as the purity of the libraries were assessed by using the 2100 Bioanalyzer. Sequencing was performed on an Illumina HiSeq1500 sequencer with 50 base pair single-end reads and a sequencing depth of 20 million reads per sample. For analysis, RNA-seq reads were mapped to the mouse genome (mm10) using STAR ${ }^{147}$. Expression of genes in transcripts per million was calculated with RSEM ${ }^{148}$. RNA-seq analysis was performed in R (Version 3.5.3) with R-Studio (R-Studio, Inc., Version 1.1.383). Differential gene expression analysis and PCA was performed using DESeq2 (Version 1.22.2). Genes with average gene counts $<1$ were discarded and $\log _{2}$ FC shrinkage was performed using the Apeglm package ${ }^{149}$. Heatmaps were generated using pheatmap (Version 1.0.12) and graphs were plotted with ggplot2 (Version 3.0.2). Tables containing differentially expressed genes were created using Microsoft Excel version 16.34

ScRNA-seq and data processing. $\mathrm{MHCII}^{+}$cells from splenocytes of 9-day-old female Clec $9 a^{\text {cre/cre }} \operatorname{Rosa}^{T O M}$ mice were sorted after gating out CD19 ${ }^{+} \mathrm{B}$ cells and autofluorescence ${ }^{+} \mathrm{F} 4 / 80^{\mathrm{hi}}$ macrophages. To increase cell yield, spleens from three mice were pooled. Sorted cells were pelleted, resuspended at $1 \times 10^{3}$ cells $/ \mu \mathrm{L}$ in PBS containing $0.04 \%$ bovine serum albumin, and loaded onto the Chromium Controller (10X Genomics). Samples were processed for single-cell encapsulation and cDNA library generation using the Chromium Single Cell $3^{\prime}$ v3 Reagent Kits (10X Genomics). The constructed library was sequenced on an Illumina HiSeq2500 (Rapid Run) sequencer with $28($ read 1$)+91($ read 2$)$ base pair paired-end reads and a sequencing depth of 320 million reads in total. Sequencing data were processed using 10X Genomics Cell Ranger v3.0.2 pipeline. Sequencing reads were mapped to the mouse genome (mm10) using STAR ${ }^{147}$ after spiking in the 
sequences of iCRE (GenBank ID: AY056050.1), the predicted transcript of the unrecombined Rosa locus and Tomato sequence (GenBank ID: AY678269.1). Cell Ranger's count pipeline was run under default parameters. The output of Cell Ranger's count pipeline was a gene-barcode matrix consisting of $\sim 1788$ cellular barcodes with 179,245 mean reads per barcode. This matrix was inserted to the $\mathrm{R}$ (Version 3.5.3) software package Seurat (v3.0.2) ${ }^{86,87}$ for all downstream analyses. Cells expressing $<200$ genes, having $>7.5 \%$ of mitochondrial associated genes and genes detected in $<3$ cells were removed from further analysis according to the software suggestions. In addition, cells were scored based on their cell cycle score and the differences between G2M and S phase cells were regressed. The SCtransform package was used to normalize, scale, and find the variable features of the dataset before PCA. Genes associated with the top 40 PCs were used for graph-based cluster identification (resolution 1.3) and subsequent dimensionality reduction using UMAP. Identification of cluster defining markers and differential expression analysis were performed using the FindAllMarkers and FindMarkers commands of the Seurat package. To score single cells based on their Tomato expression, we calculated the ratio of normalized Tomato reads per cell to normalized reads per cell of the predicted transcript of the unrecombined Rosa locus (Ratio Tom/unrec. Rosa). Cells with a ratio above 0.5 or below -0.5 were denoted $\mathrm{Tom}^{+}$or $\mathrm{Tom}^{-}$, respectively. The selected thresholds included more than $90 \%$ of the total cells in each cluster. Tables containing differentially expressed genes were created using Microsoft Excel version 16.34 .

For trajectory analysis using Palantir, we selected clusters $0,3,6,7,11$, and 14, and generated diffusion maps as described ${ }^{93}$. We provided a defined starting point in cluster 11 and used Palantir to characterize potential pseudo-time trajectories from this point. The terminal states found in the analysis were automatically calculated by the Palantir algorithm.

Cytospins and Hemacolor staining. $\mathrm{TOM}^{+} \mathrm{CDC} 2$ and $\mathrm{TOM}^{-} \mathrm{DC} 2$ were sorted from CD $11 \mathrm{c}^{+}$enriched splenocytes from 11-day-old Clec9a $a^{\text {cre/cre }}$ RosaTOM mice as live, single, autofluorescence-negative, $\mathrm{CD}_{11 \mathrm{c}^{+} \mathrm{MHCII}}{ }^{\mathrm{CD}} 11 \mathrm{~b}^{+} \mathrm{TOM}^{+}$or $\mathrm{TOM}^{-}$ cells. Cells $\left(2 \times 10^{4}\right)$ were spun onto a microscope slide in a Shandon Cytospin 2 for 5 min at 8000 r.p.m. and stained with Hemacolor ${ }^{\circledR}$ rapid staining kit (Merck). Microscopy was performed at the Core Facility Bioimaging of the Biomedical Center using a Leica DM 2500 LED microscope with a $\times 100$ magnification.

Bone marrow FLT3L cultures. Bone marrow cells from adult $\mathrm{Clec} 9 a^{\text {cre } /+} \mathrm{Rosa}^{T O M}$ (CD45.2) were isolated as described above.

After lineage depletion using negative selection (lineage: CD3, TER119, Ly6G, CD19), CLPs were sorted as live, single, lin ${ }^{-} \mathrm{CD} 115^{-} \mathrm{CD} 117^{\text {int }} \mathrm{CD} 135^{+} \mathrm{CD} 127^{+}$ $\mathrm{B}^{2} 20^{-} \mathrm{TOMATO}^{-}$cells. CLPs $\left(10^{4}\right)$ were seeded in $300 \mu \mathrm{L}$ complete medium (RPMI supplemented with 10\% FCS, penicillin/streptomycin, 1\% non-essential amino acids, $1 \%$ sodium pyruvate, $1 \%$ L-glutamine, $0.05 \mathrm{mM} \beta$-mercaptoethanol) in a 48-well plate together with $1.5 \times 10^{5}$ total bone marrow cells isolated from congenic B6.SJL (CD45.1) mice. As controls, total bone marrow cells from Clec $9 a^{\text {cre/ }+}$ RosaTOM and B6.SJL congenic mice were seeded at a $1: 1$ ratio. FLT3L (purified from supernatant of CHO-flk2 cell line, a kind gift from Dr. Anne Krug, Institute for Immunology, Biomedical Center, Munich) was added to all wells at a concentration of $50 \mathrm{ng} / \mathrm{mL}$. Culture wells were left unperturbed for 7 days and then the culture output was analyzed by flow cytometry.

In vitro T-cell proliferation. DCs were sorted from $\mathrm{CD} 11 \mathrm{c}^{+}$enriched cells from spleen of 2-week-old and adult Clec $9 a^{\text {cre/cre }} \mathrm{Rosa}^{T O M}$ mice, as live, single, autofluorescent-negative, $\mathrm{CD} 11 \mathrm{c}^{+} \mathrm{MHCII}^{+} \mathrm{CD}_{11 b^{+}} \mathrm{TOMATO}^{+}$, or $\mathrm{TOMATO}^{-}$cells. In some experiments, DCs were further subset based on ESAM and ROR $\gamma \mathrm{t}$ expression, as indicated. In experiments comparing cDC2 from SPF and GF mice, cDC2 were sorted from CD11c-enriched splenocytes as live, single, autofluorescence-negative, $\mathrm{CD} 11 \mathrm{c}^{+} \mathrm{MHCII}{ }^{+} \mathrm{CD} 11 \mathrm{~b}^{+}$cells. Sorted cells were incubated in the wells of a V-bottom 96-well plate with $10 \mu \mathrm{g} / \mathrm{mL}$ chicken OVA peptide $\left(\mathrm{OVA}_{323-339}\right.$, InvivoGen) for $3 \mathrm{~h}$ in complete medium (prepared as indicated above). After washing two times to remove any residual $\mathrm{OVA}_{323-339}$ DCs were resuspended in complete medium, serially diluted, and co-cultured at the indicated ratios with naive CTV-labeled OT-II cells from adult mice. Naive OT-II cells were isolated as described above and labeled with CTV (Thermo Fisher Scientific). First, OT-II cells were resuspended in PBS at $20 \times 10^{6}$ cells $/ \mathrm{mL}$ and an equal volume of CTV working solution was added to a final concentration of $5 \mathrm{mM}$. Cells were incubated for $20 \mathrm{~min}$ at $37^{\circ} \mathrm{C}$ in the dark and were mixed at the midpoint of the incubation. An excess of pre-warmed complete medium was added and after a 5 min incubation, cells were washed with PBS. Cultures were supplemented with $20 \mathrm{ng} / \mathrm{mL}$ IL-12 (PeproTech) and $10 \mu \mathrm{g} / \mathrm{mL}$ anti-IL-4 (Biolegend) for Th1; $5 \mathrm{ng} / \mathrm{mL}$ TGF- $\beta, 10 \mu \mathrm{g} / \mathrm{mL}$ anti-IL- 4 , and $10 \mu \mathrm{g} / \mathrm{mL}$ anti-IFN- $\gamma$ for Treg; $5 \mathrm{ng} / \mathrm{mL}$ TGF- $\beta$, $20 \mathrm{ng} / \mathrm{mL}$ IL-6, $10 \mu \mathrm{g} / \mathrm{mL}$ anti-IL-4, and $10 \mu \mathrm{g} / \mathrm{mL}$ anti-IFN- $\gamma$ (all Biolegend) for Th17 conditions. After 3.5 days of culture, supernatant was collected from each well and cells were restimulated with $10 \mathrm{ng} / \mathrm{mL}$ phorbol 12 -myristate 13 -acetate (PMA) (Calbiochem) and $1 \mu \mathrm{g} / \mathrm{mL}$ ionomycin (Sigma-Aldrich) for $5 \mathrm{~h}$. After $2 \mathrm{~h}$, brefeldin A $(5 \mu \mathrm{g} / \mathrm{mL}$, Biolegend) was added for the remaining $3 \mathrm{~h}$. Cytokines and Foxp3 expression were detected by intracellular staining. Cytokine secretion in culture supernatants was quantified using LEGENDplex ${ }^{\mathrm{TM}}$ Mouse Th Cytokine Panel (Biolegend) according to the manufacturer's instructions. For co-culture experiments with OVA, DCs were sorted as above resuspended in complete medium in the wells of a V-bottom 96-well plate, serially diluted and co-cultured at the indicated ratios with CTV-labeled naive OT-II cells in the presence of $20 \mu \mathrm{g} / \mathrm{mL}$ OVA (Hyglos). After 4 days of culture, cytokine production was assessed as above.

Antigen targeting. Antigen targeting was performed as described 25,107 . To establish targeting specificity 2-week-old Clec $9 a^{\text {cre/ } /+}$ Rosa $a^{T O M}$ mice were injected intraperitoneally (i.p.) with $10 \mu \mathrm{g} \alpha \mathrm{DCIR} 2-\mathrm{OVA}$ or $10 \mu \mathrm{g}$ OVA coupled isotype control antibody. Mice were killed $12 \mathrm{~h}$ later and splenocytes were isolated by mechanically disrupting the spleens through a $70 \mu \mathrm{m}$ strainer and washing once with PBS containing $1 \%$ FCS. Splenic single-cell suspensions were then enriched for $\mathrm{CD} 11 \mathrm{c}^{+}$cells by positive selection using anti-CD11c magnetic beads and LS columns (Miltenyi). PBS containing 1\% FCS was used throughout the procedures of isolation, enrichment and preparation of cells for sorting. $\mathrm{TOM}^{+} \mathrm{CDC} 2$ and $\mathrm{TOM}^{-}$DC2 were sorted as CD11 ${ }^{+} \mathrm{B}_{2} 20^{-} \mathrm{Ly}_{6} \mathrm{G}^{-} \mathrm{Ly}_{6 \mathrm{C}^{-}} \mathrm{CD} 90.2^{-} \mathrm{CD} 11 \mathrm{~b}^{+}$

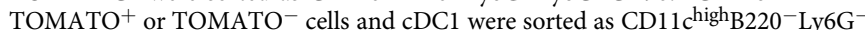
Ly6C ${ }^{-} \mathrm{CD} 90.2^{-} \mathrm{CD} 24^{+} \mathrm{XCR}-1^{+}$cells. Sorted DCs were co-cultured with CTVlabeled naive CD90.1 OT-II cells in complete medium. After 3.5 days, supernatant was collected from each well and OT-II proliferation analyzed by flow cytometry. For targeting experiments with adjuvant, 2-week-old and adult, Clec $9 a^{\text {cre/ }+}$ RosaTOM mice were injected i.p. with $10 \mu \mathrm{g}$ of $\alpha$ DCIR2-OVA plus $0.2 \mu \mathrm{g} / \mathrm{g}$ body weight of CpG-B ODN 1826 (Sigma-Aldrich). DC populations were sorted and cocultured with CTV-labeled naive CD90.1 OT-II cells as above. After 3.5 days, OTII cells were restimulated with PMA/ionomycin for $5 \mathrm{~h}$ in the presence of Brefeldin A and cytokine production and Foxp3 expression assessed by flow cytometry as described above. T-cell proliferation, cytokine production after restimulation, and quantification of secreted cytokines in culture supernatants were assessed as above.

TOMATO stability in vitro. $\mathrm{TOM}^{+} \mathrm{CDC} 2$ and $\mathrm{TOM}^{-} \mathrm{DC} 2$ from 1-week-old Clec $9 a^{\text {cre/cre }}$ Rosa $^{T O M}$ mice were sorted as above. Cells $\left(2.5 \times 10^{3}\right)$ were seeded in $200 \mu \mathrm{L}$ complete medium together with $10^{5}$ total splenocytes from CD45.1 congenic mice. Cultures were supplemented with $50 \mathrm{ng} / \mathrm{mL}$ murine recombinant $\mathrm{GM}$ CSF (PeproTech) and $200 \mathrm{ng} / \mathrm{mL}$ murine recombinant FLT3L (R\&D Systems). After $24 \mathrm{~h}$, cells were collected and analyzed by flow cytometry.

In vitro phagocytosis. CD11c-enriched splenocytes $\left(5 \times 10^{4}\right)$ from 2-week-old and adult Clec $9 a^{\text {cre } /+}$ Rosa $^{\text {TOM }}$ mice cells were cultured with beads (FluoSpheres ${ }^{\circledR}$, Polystyrene Microspheres, $1.0 \mu \mathrm{m}$, yellow-green fluorescent (505/515)), Invitrogen) at a $50: 1$ bead to cell ratio for $2 \mathrm{~h}$ at $37^{\circ} \mathrm{C}$ in humidified atmosphere containing $5 \% \mathrm{CO}_{2}$ in complete medium. To inhibit phagocytosis, cells were pretreated with $10 \mu \mathrm{g} / \mathrm{ml}$ cytochalasin D (Sigma-Aldrich) for $1 \mathrm{~h}$ at $37^{\circ} \mathrm{C}$. After incubation, antibody staining for surface epitopes was performed as described above and phagocytosis of beads by $\mathrm{CDC} 2$ was quantified by flow cytometry.

In vitro stimulation and cytokine production. $\mathrm{TOM}^{+} \mathrm{cDC}^{\mathrm{C}}$ and $\mathrm{TOM}^{-} \mathrm{DC} 2$ from 2-week-old Clec $9 a^{\text {cre } /+}$ Rosa $^{T O M}$ mice and $\mathrm{TOM}^{+}$cDC2 from adult Clec $9 a^{\text {cre } /+}$ Rosa ${ }^{T O M}$ mice were sorted as above. Then, $0.7 \times 10^{6}$ cells $/ \mathrm{mL}$ were stimulated in a total volume of $50 \mu \mathrm{L}$ complete medium in 96-well V-bottom plates with $0.5 \mu \mathrm{g} / \mathrm{mL}$ CpG-B ODN 1826 (Sigma). After 18-20 h, cytokine secretion was quantified using LEGENDplex ${ }^{\mathrm{TM}}$ Mouse Inflammation Panel and LEGENDplex ${ }^{\mathrm{TM}}$ Mouse Cytokine Panel 2 for IL-12p40 (both from Biolegend) according to the manufacturer's instructions.

Statistical analysis. Statistical significance was calculated in Prism 7 software (GraphPad) using two-tailed $t$-test with Welch's correction (unless otherwise stated) or two-tailed paired $t$-test. For multiple comparisons, one-way analysis of variance with Tukey's test (unless otherwise stated) was performed. A $p$-value $<$ 0.05 was considered significant.

Reporting summary. Further information on research design is available in the Nature Research Reporting Summary linked to this article.

\section{Data availability}

The authors declare that the data supporting the findings of this study are available within the paper and its Supplementary Files. Raw data are available from the authors upon reasonable request. Datasets related to bulk and single-cell sequencing experiments that were generated and analyzed for the current study have been deposited and made publicly available in the Gene Expression Omnibus under the accession number GSE151595. The sequences of iCRE and Tomato used for the single-cell RNA sequencing analysis are publicly available and can be found under the GenBank IDs AY056050.1 and AY678269.1, respectively. Source data are provided with this paper. 
Received: 16 April 2020; Accepted: 13 December 2020;

Published online: 19 January 2021

\section{References}

1. Whittaker, E., Goldblatt, D., McIntyre, P. \& Levy, O. Neonatal immunization: rationale, current future prospects. Front. Immunol. 9, 1069-10 (2018).

2. Zaghouani, H., Hoeman, C. M. \& Adkins, B. Neonatal immunity: faulty Thelpers and the shortcomings of dendritic cells. Trends Immunol. 30, 585-591 (2009).

3. Zhang, X., Zhivaki, D. \& Lo-Man, R. Unique aspects of the perinatal immune system. Nat. Rev. Immunol. 17, 495-507 (2017).

4. Coffman, R. L., Sher, A. \& Seder, R. A. Vaccine adjuvants: putting innate immunity to work. Immunity 33, 492-503 (2010).

5. Guilliams, M. et al. Dendritic cells, monocytes and macrophages: a unified nomenclature based on ontogeny. Nat. Rev. Immunol. 14, 571-578 (2014).

6. Merad, M., Sathe, P., Helft, J., Miller, J. \& Mortha, A. The dendritic cell lineage: ontogeny and function of dendritic cells and their subsets in the steady state and the inflamed setting. Annu. Rev. Immunol. 31, 563-604 (2013).

7. Lehmann, C. et al. Direct delivery of antigens to dendritic cells via antibodies specific for endocytic receptors as a promising strategy for future therapies. Vaccines 4, 8-32 (2016).

8. Kastenmuller, W., Kastenmüller, K., Kurts, C. \& Seder, R. A. Dendritic celltargeted vaccines-hope or hype? Nat. Rev. Immunol. 14, 705-711 (2014).

9. Dakic, A. et al. Development of the dendritic cell system during mouse ontogeny. J. Immunol. 172, 1018-1027 (2004).

10. Sun, C.-M., Fiette, L., Tanguy, M., Leclerc, C. \& Lo-Man, R. Ontogeny and innate properties of neonatal dendritic cells. Blood 102, 585-591 (2003).

11. Prabhu, S. B. et al. Comparison of human neonatal and adult blood leukocyte subset composition phenotypes. PLoS ONE 11, e0162242-17 (2016).

12. Muthukkumar, S., Goldstein, J. \& Stein, K. E. The ability of B cells and dendritic cells to present antigen increases during ontogeny. J. Immunol. 165, 4803-4813 (2000).

13. Langrish, C. L., Buddle, J. C., Thrasher, A. J. \& Goldblatt, D. Neonatal dendritic cells are intrinsically biased against Th-1 immune responses. Clin. Exp. Immunol. 128, 118-123 (2002).

14. Goriely, S. et al. Deficient IL-12(p35) gene expression by dendritic cells derived from neonatal monocytes. J. Immunol. 166, 2141-2146 (2001).

15. Granot, T. et al. Dendritic cells display subset and tissue-specific maturation dynamics over human life. Immunity 46, 504-515 (2017).

16. Lee, H.-H. et al. Delayed maturation of an IL-12-producing dendritic cell subset explains the early Th2 bias in neonatal immunity. J. Exp. Med. 205, 2269-2280 (2008).

17. Torres, D. et al. IL-12p40/IL-10 producing preCD8a/Clec9A+ dendritic cells are induced in neonates upon Listeria monocytogenes infection. PLoS Pathog. 12, e1005561 (2016).

18. Upham, J. W. et al. Development of interleukin-12-producing capacity throughout childhood. Infect. Immun. 70, 6583-6588 (2002).

19. Vollstedt, S. et al. Flt3 ligand-treated neonatal mice have increased innate immunity against intracellular pathogens and efficiently control virus infections. J. Exp. Med. 197, 575-584 (2003).

20. Vollstedt, S. et al. Treatment of neonatal mice with Flt3 ligand leads to changes in dendritic cell subpopulations associated with enhanced IL-12 and IFN-a production. Eur. J. Immunol. 34, 1849-1860 (2004).

21. Durai, V. \& Murphy, K. M. Functions of murine dendritic cells. Immunity 45, 719-736 (2016).

22. Hildner, K. et al. Batf3 deficiency reveals a critical role for CD8 $\alpha+$ dendritic cells in cytotoxic T cell immunity. Science 322, 1097-1100 (2008).

23. Reis e Sousa, C. et al. In vivo microbial stimulation induces rapid CD40 ligand-independent production of interleukin 12 by dendritic cells and their redistribution to T cell areas. J. Exp. Med. 186, 1819-1829 (1997).

24. Mashayekhi, M. et al. CD8a+ dendritic cells are the critical source of interleukin-12 that controls acute infection by Toxoplasma gondii Tachyzoites. Immunity 35, 249-259 (2011).

25. Dudziak, D. et al. Differential antigen processing by dendritic cell subsets in vivo. Science 315, 107-111 (2007).

26. Shin, C. et al. Intrinsic features of the CD8 $\alpha$ - dendritic cell subset in inducing functional T follicular helper cells. Immunol. Lett. 172, 21-28 (2016).

27. Persson, E. K. et al. IRF4 transcription-factor-dependent CD103+CD11b+ dendritic cells drive mucosal $\mathrm{T}$ helper 17 cell differentiation. Immunity 38, 958-969 (2013).

28. Schlitzer, A. et al. IRF4 transcription factor-dependent CD11b + dendritic cells in human and mouse control mucosal IL-17 cytokine responses. Immunity 38, 970-983 (2013).

29. Tussiwand, R. et al. Klf4 expression in conventional dendritic cells is required for T helper 2 cell responses. Immunity 42, 916-928 (2015).
30. de Kleer, I. M. et al. Perinatal activation of the interleukin-33 pathway promotes type 2 immunity in the developing lung. Immunity 45, 1285-1298 (2016).

31. Pakalniškytè, D. \& Schraml, B. U. Tissue-specific diversity and functions of conventional dendritic cells. Adv. Immunol. 134, 89-135 (2017).

32. Ruckwardt, T. J., Morabito, K. M., Bar-Haim, E., Nair, D. \& Graham, B. S. Neonatal mice possess two phenotypically and functionally distinct lungmigratory CD103+ dendritic cell populations following respiratory infection. Mucosal Immunol. 11, 186-198 (2018).

33. Lau-Kilby, A. W. et al. Type I IFN ineffectively activates neonatal dendritic cells limiting respiratory antiviral T-cell responses. Mucosal Immunol. 13, 371-380 (2019)

34. Papaioannou, N. E., Pasztoi, M. \& Schraml, B. U. Understanding the functional properties of neonatal dendritic cells: a doorway to enhance vaccine effectiveness? Front. Immunol. 9, 553-558 (2019).

35. Ruckwardt, T. J., Malloy, A. M. W., Morabito, K. M. \& Graham, B. S. Quantitative and qualitative deficits in neonatal lung-migratory dendritic cells impact the generation of the CD8 $+\mathrm{T}$ cell response. PLoS Pathog. 10, e1003934 EP (2014)

36. Sharma, P., Levy, O. \& Dowling, D. J. The TLR5 agonist Flagellin shapes phenotypical and functional activation of lung mucosal antigen presenting cells in neonatal mice. Front. Immunol. 11, 430-13 (2020).

37. Gollwitzer, E. S. et al. Lung microbiota promotes tolerance to allergens in neonates via PD-L1. Nat. Med. 20, 642-647 (2014).

38. Bachus, $H$. et al. Impaired tumor-necrosis-factor- $\alpha$-driven dendritic cell activation limits lipopolysaccharide-induced protection from allergic inflammation in infants. Immunity 50, 225-240.e4 (2019).

39. Lewis, S. M., Williams, A. \& Eisenbarth, S. C. Structure and function of the immune system in the spleen. Sci. Immunol. 4, eaau6085 (2019).

40. Popescu, D.-M. et al. Decoding human fetal liver haematopoiesis. Nature 574, 365-371 (2019)

41. Schulz, C. et al. A lineage of myeloid cells independent of Myb and hematopoietic stem cells. Science 336, 86-90 (2012).

42. Gentek, R. et al. Hemogenic endothelial fate mapping reveals dual developmental origin of mast cells. Immunity 48, 1160-1171.e5 (2018).

43. McGovern, N. et al. Human fetal dendritic cells promote prenatal T-cell immune suppression through arginase-2. Nature 546, 662-666 (2017).

44. Naik, S. H. et al. Development of plasmacytoid and conventional dendritic cell subtypes from single precursor cells derived in vitro and in vivo. Nat. Immunol. 8, 1217-1226 (2007).

45. Onai, N. et al. Identification of clonogenic common Flt3+M-CSFR+ plasmacytoid and conventional dendritic cell progenitors in mouse bone marrow. Nat. Immunol. 8, 1207-1216 (2007).

46. Breton, G. et al. Circulating precursors of human CD1c+ and CD141+ dendritic cells. J. Exp. Med. 212, 401-413 (2015).

47. Lee, J. et al. Restricted dendritic cell and monocyte progenitors in human cord blood and bone marrow. J. Exp. Med. 212, 385-399 (2015).

48. Schraml, B. U. et al. Genetic tracing via DNGR-1 expression history defines dendritic cells as a hematopoietic lineage. Cell 154, 843-858 (2013).

49. Liu, K. et al. In vivo analysis of dendritic cell development and homeostasis Science 324, 392-397 (2009).

50. Caminschi, I. et al. The dendritic cell subtype-restricted C-type lectin Clec9A is a target for vaccine enhancement. Blood 112, 3264-3273 (2008).

51. Joffre, O. P., Sancho, D., Zelenay, S., Keller, A. M. \& Reis e Sousa, C. Efficien and versatile manipulation of the peripheral CD4+ T-cell compartment by antigen targeting to DNGR-1/CLEC9A. Eur. J. Immunol. 40, 1255-1265 (2010)..

52. Sancho, D. et al. Tumor therapy in mice via antigen targeting to a novel, DC restricted C-type lectin. J. Clin. Invest. 118, 2098-2110 (2008).

53. Cabeza-Cabrerizo, M. et al. Tissue clonality of dendritic cell subsets and emergency DCpoiesis revealed by multicolor fate mapping of DC progenitors. Sci. Immunol. 4, eaaw1941 (2019).

54. Salei, N. et al. The kidney contains ontogenetically distinct dendritic cell and macrophage subtypes throughout development that differ in their inflammatory properties. J. Am. Soc. Nephrol. 31, 257-278 (2020).

55. Meredith, M. M. et al. Expression of the zinc finger transcription factor $\mathrm{zDC}$ (Zbtb46, Btbd4) defines the classical dendritic cell lineage. J. Exp. Med. 209, 1153-1165 (2012)

56. Satpathy, A. T. et al. Zbtb46 expression distinguishes classical dendritic cells and their committed progenitors from other immune lineages. J. Exp. Med. 209, 1135-1152 (2012).

57. Adkins, B., Leclerc, C. \& Marshall-Clarke, S. Neonatal adaptive immunity comes of age. Nat. Rev. Immunol. 4, 553-564 (2004).

58. Bachem, A. et al. Expression of XCR1 characterizes the Batf3-dependent lineage of dendritic cells capable of antigen cross-presentation. Front. Immunol. 3, 214 (2012).

59. Lau, C. M. et al. Leukemia-associated activating mutation of Flt3 expands dendritic cells and alters T cell responses. J. Exp. Med. 213, 415-431 (2016). 
60. Bar-On, L. et al. CX3CR1+ CD8 + dendritic cells are a steady-state population related to plasmacytoid dendritic cells. Proc. Natl Acad. Sci. USA 107, 14745-14750 (2010).

61. Dicken, J. et al. Transcriptional reprogramming of CD11b+Esamhi dendritic cell identity and function by loss of Runx3. PLoS ONE 8, e77490-12 (2013).

62. Lewis, K. L. et al. Notch2 receptor signaling controls functional differentiation of dendritic cells in the spleen and intestine. Immunity 35, 780-791 (2011).

63. Satpathy, A. T. et al. Notch2-dependent classical dendritic cells orchestrate intestinal immunity to attaching-and-effacing bacterial pathogens. Nat. Immunol. 14, 937-948 (2013).

64. Liu, J. et al. Non-parallel recombination limits cre-loxP-based reporters as precise indicators of conditional genetic manipulation. Genesis 51, 436-442 (2013).

65. McKenna, H. J. et al. Mice lacking flt3 ligand have deficient hematopoiesis affecting hematopoietic progenitor cells, dendritic cells, and natural killer cells. Blood 95, 3489-3497 (2000).

66. Böiers, C. et al. Lymphomyeloid contribution of an immune-restricted progenitor emerging prior to definitive hematopoietic stem cells. Stem Cell 13, 535-548 (2013).

67. Gomez-Perdiguero, E. et al. Tissue-resident macrophages originate from yolksac-derived erythro-myeloid progenitors. Nature 518, 547-551 (2015).

68. Mucenski, M. L. et al. A functional c-myb gene is required for normal murine fetal hepatic hematopoiesis. Cell 65, 677-689 (1991).

69. Ardavín, C., Wu, L., Li, C.-L. \& Shortman, K. Thymic dendritic cells and $\mathrm{T}$ cells develop simultaneously in the thymus from a common precursor population. Nature 362, 761-763 (1993).

70. Becker, A. M. et al. IRF-8 extinguishes neutrophil production and promotes dendritic cell lineage commitment in both myeloid and lymphoid mouse progenitors. Blood 119, 2003-2012 (2012).

71. Manz, M. G., Traver, D., Miyamoto, T., Weissman, I. L. \& Akashi, K. Dendritic cell potentials of early lymphoid and myeloid progenitors. Blood $\mathbf{9 7}$, 3333-3341 (2001).

72. $\mathrm{Wu}, \mathrm{L}$. et al. Development of thymic and splenic dendritic cell populations from different hemopoietic precursors. Blood 98, 3376-3382 (2001).

73. Izon, D. et al. A common pathway for dendritic cell and early B cell development. J. Immunol. 167, 1387-1392 (2001).

74. Salvermoser, J. et al. Clec9a-mediated ablation of conventional dendritic cells suggests a lymphoid path to generating dendritic cells in vivo. Front. Immunol. 9, 563-15 (2018).

75. Igarashi, H., Gregory, S. C., Yokota, T., Sakaguchi, N. \& Kincade, P. W. Transcription from the RAG1 locus marks the earliest lymphocyte progenitors in bone marrow. Immunity 17, 117-130 (2002).

76. Schlenner, S. M. et al. Fate mapping reveals separate origins of T cells and myeloid lineages in the thymus. Immunity 32, 426-436 (2010).

77. Werner, Y. et al. Cxcr4 distinguishes HSC-derived monocytes from microglia and reveals monocyte immune responses to experimental stroke. Nat. Neurosci. 23, 351-362 (2020).

78. Gibbings, S. L. et al. Transcriptome analysis highlights the conserved difference between embryonic and postnatal-derived alveolar macrophages. Blood 126, 1357-1366 (2015).

79. Lavin, Y. et al. Tissue-resident macrophage enhancer landscapes are shaped by the local microenvironment. Cell 159, 1312-1326 (2014).

80. Smith, N. L. et al. Developmental origin governs CD8+ T cell fate decisions during infection. Cell 174, 117-130.e14 (2018)

81. Mold, J. E. et al. Fetal and adult hematopoietic stem cells give rise to distinct T cell lineages in humans. Science 330, 1695-1699 (2010).

82. Beaudin, A. E. et al. A transient developmental hematopoietic stem cell gives rise to innate-like B and T cells. Stem Cell 19, 768-783 (2016).

83. Gury-BenAri, M. et al. The spectrum and regulatory landscape of intestinal innate lymphoid cells are shaped by the microbiome. Cell 166, 1231-1239.e13 (2016).

84. Robinette, M. L. et al. Transcriptional programs define molecular characteristics of innate lymphoid cell classes and subsets. Nat. Immunol. 16, 306-317 (2015).

85. Spits, H. \& Cupedo, T. Innate lymphoid cells: emerging insights in development, lineage relationships, and function. Annu. Rev. Immunol. 30, 647-675 (2012).

86. Satija, R., Farrell, J. A., Gennert, D., Schier, A. F. \& Regev, A. Spatial reconstruction of single-cell gene expression data. Nat. Biotechnol. 33, 495-502 (2015).

87. Stuart, T. et al. Comprehensive integration of single-cell data. Cell 177, 1888-1902.e21 (2019).

88. Liu, Y., Beyer, A. \& Aebersold, R. On the dependency of cellular protein levels on mRNA abundance. Cell 165, 535-550 (2016).

89. Shimshek, D. R. et al. Codon-improved Cre recombinase (iCre) expression in the mouse. Genesis 32, 19-26 (2002).

90. Miller, J. C. et al. Deciphering the transcriptional network of the dendritic cell lineage. Nat. Immunol. 13, 888-899 (2012).
91. Madisen, L. et al. A robust and high-throughput Cre reporting and characterization system for the whole mouse brain. Nat. Neurosci. 13, 133-140 (2010).

92. Brown, C. C. et al. Transcriptional basis of mouse and human dendritic cell heterogeneity. Cell 179, 846-863.e24 (2019).

93. Setty, M. et al. Characterization of cell fate probabilities in single-cell data with Palantir. Nat. Biotechnol. 37, 451-460 (2019).

94. Eberl, G. \& Littman, D. R. Thymic origin of intestinal $\alpha ß \mathrm{~T}$ cells revealed by fate mapping of ROR $\gamma \mathrm{t}+$ cells. Science 305, 248 (2004).

95. Bazhin, A. V. et al. Interferon- $\alpha$ up-regulates the expression of PD-L1 molecules on immune cells through STAT3 and p38 signaling. Front. Immunol. 9, 119-13 (2018)

96. Nguyen-Pham, T.-N. et al. Type I and II interferons enhance dendritic cell maturation and migration capacity by regulating CD38 and CD74 that have synergistic effects with TLR agonists. Cell. Mol. Immunol. 8, 341-347 (2011).

97. Xiao, X. et al. The costimulatory receptor OX40 inhibits interleukin-17 expression through activation of repressive chromatin remodeling pathways. Immunity 44, 1271-1283 (2016)

98. D'Addio, F. et al. The link between the PDL1 costimulatory pathway and Th17 in fetomaternal tolerance. J. Immunol. 187, 4530-4541 (2011).

99. Browning, L. M. et al. TGF- $\beta$-mediated enhancement of TH17 cell generation is inhibited by bone morphogenetic protein receptor $1 a$ signaling. Sci. Signal. 11, eaar2125 (2018).

100. Blois, S. M. et al. A pivotal role for galectin-1 in fetomaternal tolerance. Nat. Med. 13, 1450-1457 (2007)

101. Cedeno-Laurent, F. \& Dimitroff, C. J. Galectin-1 research in T cell immunity: past, present and future. Clin. Immunol. 142, 107-116 (2012).

102. Delgoffe, G. M. et al. Stability and function of regulatory T cells is maintained by a neuropilin-1-semaphorin-4a axis. Nature 501, 252-256 (2013).

103. Garín, M. I. et al. Galectin-1: a key effector of regulation mediated by CD4+CD25+ T cells. Blood 109, 2058-2065 (2006).

104. Heink, S. et al. Trans-presentation of IL- 6 by dendritic cells is required for the priming of pathogenic TH17 cells. Nat. Immunol. 18, 74-85 (2016).

105. Jiang, H.-R. et al. Galectin-3 deficiency reduces the severity of experimental autoimmune encephalomyelitis. J. Immunol. 182, 1167-1173 (2009).

106. Lynch, J. P. et al. Plasmacytoid dendritic cells protect from viral bronchiolitis and asthma through semaphorin $4 \mathrm{a}$-mediated $\mathrm{T}$ reg expansion. J. Exp. Med 215, 537-557 (2017).

107. Lehmann, C. H. K. et al. DC subset-specific induction of T cell responses upon antigen uptake via $\mathrm{Fc} \gamma$ receptors in vivo. J. Exp. Med. 214, 1509-1528 (2017).

108. Kovarik, J. et al. Adjuvant effects of $\mathrm{CpG}$ oligodeoxynucleotides on responses against T-independent type 2 antigens. Immunology 102, 67-76 (2001).

109. Kovarik, J. et al. CpG oligodeoxynucleotides can circumvent the Th2 polarization of neonatal responses to vaccines but may fail to fully redirect Th2 responses established by neonatal priming. J. Immunol. 162, 1611-1617 (1999).

110. Meyer, C. U. et al. Dendritic cells change IL-27 production pattern during childhood. BMC Res. Notes 8, 232-233 (2015).

111. Leung, G. A. et al. The lymphoid-associated interleukin 7 receptor (IL7R) regulates tissue-resident macrophage development. Development 146, dev176180-25 (2019)

112. Christensen, J. L., Wright, D. E., Wagers, A. J. \& Weissman, I. L. Circulation and chemotaxis of fetal hematopoietic stem cells. PLoS Biol. 2, e75-10 (2004).

113. Perdiguero, E. G. \& Geissmann, F. The development and maintenance of resident macrophages. Nat. Immunol. 17, 2-8 (2016).

114. Ginhoux, F. \& Guilliams, M. Tissue-resident macrophage ontogeny and homeostasis. Immunity 44, 439-449 (2016).

115. Schneider, C. et al. Tissue-resident group 2 innate lymphoid cells differentiate by layered ontogeny and in situ perinatal priming. Immunity 50, 1425-1438. e5 (2019).

116. Helft, J. et al. Dendritic cell lineage potential in human early hematopoietic progenitors. Cell Rep. 20, 529-537 (2017).

117. Villani, A.-C. et al. Single-cell RNA-seq reveals new types of human blood dendritic cells, monocytes, and progenitors. Science 356, eaah4573-14 (2017).

118. Dress, R. J. et al. Plasmacytoid dendritic cells develop from Ly6D+ lymphoid progenitors distinct from the myeloid lineage. Nat. Immunol. 20, 852-864 (2019).

119. Rodrigues, P. F. et al. Distinct progenitor lineages contribute to the heterogeneity of plasmacytoid dendritic cells. Nat. Immunol. 19, 711-722 (2018).

120. Schraml, B. U., Reis, E. \& Sousa, C. ScienceDirect defining dendritic cells. Curr. Opin. Immunol. 32, 13-20 (2015).

121. Gosselin, D. et al. An environment-dependent transcriptional network specifies human microglia identity. Science 356, eaal3222-13 (2017).

122. Gosselin, D. et al. Environment drives selection and function of enhancers controlling tissue-specific macrophage identities. Cell 159, 1327-1340 (2014). 
123. van de Laar, L. et al. Yolk sac macrophages, fetal liver, and adult monocytes can colonize an empty niche and develop into functional tissue-resident macrophages. Immunity 44, 755-768 (2016).

124. Janela, B. et al. A subset of type I conventional dendritic cells controls cutaneous bacterial infections through VEGFa-mediated recruitment of neutrophils. Immunity 50, 1069-1083.e8 (2019).

125. Leylek, R. et al. Integrated cross-species analysis identifies a conserved transitional dendritic cell population. Cell Rep. 29, 3736-3750.e8 (2019).

126. Briseño, C. G. et al. Notch2-dependent DC2s mediate splenic germinal center responses. Proc. Natl Acad. Sci. USA 115, 10726-10731 (2018).

127. Hirahara, K. et al. Interleukin-27 priming of T cells controls IL-17 production in trans via induction of the ligand PD-L1. Immunity 36, 1017-1030 (2012).

128. Francisco, L. M., Sage, P. T. \& Sharpe, A. H. The PD-1 pathway in tolerance and autoimmunity. Immunol. Rev. 236, 219-242 (2010).

129. Hunter, C. A. New IL-12-family members: IL-23 and IL-27, cytokines with divergent functions. Nat. Rev. Immunol. 5, 521-531 (2005).

130. Kilgore, A. M. et al. IL-27p28 production by XCR1+ dendritic cells and monocytes effectively predicts adjuvant-elicited CD8 $+\mathrm{T}$ cell responses. Immunohorizons 2, 1-11 (2018).

131. Ng, T. H. S. et al. Regulation of adaptive immunity; the role of interleukin-10. Front. Immunol. 4, 129 (2013).

132. Nabhani, Al,Z. et al. A weaning reaction to microbiota is required for resistance to immunopathologies in the adult. Immunity 50, 1276-1288.e5 (2019).

133. Bogaert, D., Weinberger, D., Thompson, C., Lipsitch, M. \& Malley, R. Impaired innate and adaptive immunity to Streptococcus pneumoniae and its effect on colonization in an infant mouse model. Infect. Immun. 77, 1613-1622 (2009).

134. Tsai, M.-H. et al. Clinical and microbiological characteristics, and impact of therapeutic strategies on the outcomes of children with candidemia. Sci. Rep. 7, 1083-1089 (2017).

135. Fedele, G., Cassone, A. \& Ausiello, C. M. T-cell immune responses to Bordetella pertussis infection and vaccination. Pathog. Dis. 73, ftv051 (2015).

136. Vogel, K. et al. Developmental induction of human T-cell responses against Candida albicans and Aspergillus fumigatus. Sci. Rep. 8, 16904 (2018).

137. Srinivas, S. et al. Cre reporter strains produced by targeted insertion of EYFP and ECFP into the ROSA26 locus. BMC Dev. Biol. 1, 4-8 (2001).

138. Qian, B.-Z. et al. CCL2 recruits inflammatory monocytes to facilitate breasttumour metastasis. Nature 475, 222-225 (2011).

139. McCormack, M. P., Forster, A., Drynan, L., Pannell, R. \& Rabbitts, T. H. The LMO2 T-cell oncogene is activated via chromosomal translocations or retroviral insertion during gene therapy but has no mandatory role in normal T-cell Development. Mol. Cell Biol. 23, 9003-9013 (2003).

140. Barnden, M. J., Allison, J., Heath, W. R. \& Carbone, F. R. Defective TCR expression in transgenic mice constructed using cDNA-based $\alpha$ - and $\beta$-chain genes under the control of heterologous regulatory elements. Immunol. Cell Biol. 76, 34-40 (1998).

141. Lochner, M. et al. In vivo equilibrium of proinflammatory IL-17+and regulatory IL-10+Foxp3+RORyt+T cells. J. Exp. Med. 205, 1381-1393 (2008).

142. Muzumdar, M. D., Tasic, B., Miyamichi, K., Li, L. \& Luo, L. A global doublefluorescent Cre reporter mouse. Genesis 45, 593-605 (2007).

143. Luche, H., Weber, O., Rao, T. N., Blum, C. \& Fehling, H. J. Faithful activation of an extra-bright red fluorescent protein in 'knock-in' Cre-reporter mice ideally suited for lineage tracing studies. Eur. J. Immunol. 37, 43-53 (2007)..

144. Muller, U. et al. Functional role of type I and type II interferons in antiviral defense. Science 264, 1918-1921 (1994).

145. Bajénoff, M., Glaichenhaus, N. \& Germain, R. N. Fibroblastic reticular cells guide $\mathrm{T}$ lymphocyte entry into and migration within the splenic $\mathrm{T}$ cell zone. $J$. Immunol. 181, 3947-3954 (2008).

146. Schindelin, J. et al. Fiji: an open-source platform for biological-image analysis. Nat. Methods 9, 676-682 (2012).

147. Dobin, A. et al. STAR: ultrafast universal RNA-seq aligner. Bioinformatics 29, $15-21(2012)$

148. Li, B. \& Dewey, C. N. RSEM: accurate transcript quantification from RNA-Seq data with or without a reference genome. BMC Bioinformatics 12, 323 (2011).

149. Zhu, A., Ibrahim, J. G. \& Love, M. I. Heavy-tailed prior distributions for sequence count data: removing the noise and preserving large differences. Bioinformatics 35, 2084-2092 (2018).

\section{Acknowledgements}

We thank members of the Schraml lab, Anne Krug, Caetano Reis e Sousa, and Markus Sperandio for helpful discussions and critical reading of the manuscript. We acknowledge the Core Facility Flow Cytometry and the Core Facility Bioimaging at the Biomedical Center, Ludwig-Maximilians-Universität München, for providing equipment and expertise. High-throughput sequencing was performed by the laboratory for Functional Genome Analysis (LAFUGA) of the LMU Munich. Some flow cytometry experiments were performed at the Core Unit Cell Sorting and Immunomonitoring of the University Hospital Erlangen. We thank Hans-Reimer Rodewald for providing $\mathrm{Il}_{\mathrm{r}} \mathrm{rre}^{\mathrm{r}}$ mice. This work was supported by ERC Starting Grant awarded to B.S. (ERC-2016-STG 715182). Work in the Schraml lab is also funded by the Deutsche For-

schungsgemeinschaft (DFG, German Research Foundation) Emmy Noether Grant: Schr 1444/1-1 (to B.S.) and Projektnummer 360372040 - SFB 1335/P08 (to B.S.). C.O. is supported by an ERC Starting Grant (ERC-2016-STG-716718) and by DFG within CRC1371 (project P07) and FOR2599 (project P07). C.S. was supported by the SFB914 (project A10), as well as the DZHK (German Centre for Cardiovascular Research) and the BMBF (German Ministry of Education and Research) (grant 81Z0600204). D.D. received funding from the DFG (DU548/5-1, CRC1181-A7) and Agency national research (ANR)/German Research Foundation program (DU548/6-1).

\section{Author contributions}

N.E.P., N.S., S.R., K.R., J.P., V.K., C.H.K.L., R.F., J.S., D.W.G., R.M., D.M., and B.S performed experiments. N.E.P., G.S., and T.S. performed sequencing analysis. C.H.K.L. and D.D. helped with targeting experiments. C.O. provided Rore ${ }^{e G F P}$ mice, D.H. germfree mice, S.E.J. Rag $1^{\text {cre }}$ mice, and R.S. CXCR4 ${ }^{\mathrm{CreER}}$ mice, and helped in planning the corresponding experiments. S.E.J. and J.C. provided critical input for fate mapping lymphoid progenitors. C.S., G.S., D.D., and D.W. provided reagents and critical intellectual input. B.S. designed and supervised the study.

\section{Funding}

Open Access funding enabled and organized by Projekt DEAL.

\section{Competing interests}

The authors declare no competing interests.

\section{Additional information}

Supplementary information is available for this paper at https://doi.org/10.1038/s41467020-20659-2.

Correspondence and requests for materials should be addressed to B.U.S.

Peer review information Nature Communications thanks Roxane Tussiwand and the other, anonymous, reviewer(s) for their contribution to the peer review of this work. Peer reviewer reports are available.

Reprints and permission information is available at http://www.nature.com/reprints

Publisher's note Springer Nature remains neutral with regard to jurisdictional claims in published maps and institutional affiliations.

Open Access This article is licensed under a Creative Commons Attribution 4.0 International License, which permits use, sharing, adaptation, distribution and reproduction in any medium or format, as long as you give appropriate credit to the original author(s) and the source, provide a link to the Creative Commons license, and indicate if changes were made. The images or other third party material in this article are included in the article's Creative Commons license, unless indicated otherwise in a credit line to the material. If material is not included in the article's Creative Commons license and your intended use is not permitted by statutory regulation or exceeds the permitted use, you will need to obtain permission directly from the copyright holder. To view a copy of this license, visit http://creativecommons.org/ licenses/by/4.0/.

(C) The Author(s) 2021 